www.volsu.ru

DOI: https://doi.org/10.15688/nav.jvolsu.2021.1.8

UDC 903' 1:391.7

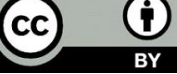

LBC 63.442.7(235.7)-417

Submitted: 01.12.2020

Accepted: 27.05 .2021

\title{
GOLD SETTINGS WITH INLAYS FROM KOSIKA ${ }^{1}$
}

\author{
Mikhail Yu. Treister \\ German Archaeological Institute, Berlin, Germany
}

\begin{abstract}
The article dwells on the finds in the burial of the Sarmatian skeptuchos of the $1^{\text {st }}$ century BC near Kosika on the Lower Volga of the gold settings, decorated using the cloisonné technique and with inlays of emeralds and glass of different colors. Three of them with inlays in the cloisonne technique, which find parallels among jewelry from the Artyukhov Burial-mound and Asia Minor, are probably dating back to the $2^{\text {nd }}$ century BC, and could originally decorate various objects. 18 other settings are characterized by the absence of loops on the rear or holes for stringing, which excludes their use as elements of necklaces or diadems. These settings find analogies among the finds from the tomb in the Burial-mound A in Karalar in Central Anatolia, in which the Galatian king Sinorix, the father of Deiotaros I (ca. 120-41/40 BC) and the grandfather of Deiotaros II the Younger (Philopator), died in the battle under Philippi in $42 \mathrm{BC}$, was possibly buried. Like by the settings from Karalar, a significant number of settings from Kosika are decorated with green inlays of emerald and beryl, which were widely used in jewelry of the Late Hellenistic and Early Imperial periods. Along with other unique items from the burial on the Lower Volga, gold settings with inlays, most likely used in the interior decoration of the grave or in the decoration of the bone handle of the ceremonial dagger, emphasize the belonging of the burial to the highest rank of the Sarmatian elite.

Key words: Lower Volga region, Kosika, Bosporus, Artyukhov Burial-mound, Asia Minor, Galatia, Karalar, settings with inlays, cloisonné, emeralds.

Citation. Treister M.Yu., 2021. Zolotye kasty so vstavkami iz Kosiki [Gold Settings with Inlays from Kosika]. Nizhnevolzhskiy Arkheologicheskiy Vestnik [The Lower Volga Archaeological Bulletin], vol. 20, no. 1, pp. 153-178. DOI: https://doi.org/10.15688/nav.jvolsu.2021.1.8
\end{abstract}

УДК 903’1:391.7

ББК 63.442.7(235.7)-417
Дата поступления статьи: 01.12.2020 Дата принятия статьи: 27.05.2021

\section{ЗОЛОТЫЕ КАСТЫ СО ВСТАВКАМИ ИЗ КОСИКИ ${ }^{1}$}

\section{Михаил Юрьевич Трейстер}

Германский археологический институт, г. Берлин, Германия

Аннотация. В статье рассматриваются найденные в погребении сарматского скептуха I в. до н.э. в Косике на Нижней Волге золотые касты, украшенные в технике клуазонне, и касты со вставками изумрудов и стекла разных цветов. Три каста со вставками в технике клуазонне, находящие аналогии среди ювелирных изделий из Артюховского кургана и Малой Азии, вероятно датирующиеся еще II в. до н.э., могли изначально украшать различные предметы. 18 остальных кастов характеризуются отсутствием петель на обороте или отверстий для нанизывания, что исключает их использование как элементов ожерелий или диадем. Эти касты $\overrightarrow{\widetilde{V}}$ находят аналогии в кастах из погребения в кургане «А» в Караларе в Центральной Анатолии, в котором, ๙ возможно, был погребен царь галатов Синорикс, отец Дейотара I (ок. 120-41/40 гг. до н.э.) и дед погибшего пํ. при Филиппах в 42 г. до н.э. Дейотара II младшего (Филопатора). Как и среди кастов из Каралара, значительное количество кастов украшены вставками зеленого цвета из изумруда и берилла, которые получили широ巳 кое распространение в ювелирных изделиях эпохи позднего эллинизма и Ранней империи. Наряду с другими у. уникальными предметами из погребения на Нижней Волге золотые касты со вставками, вероятнее всего ఓ использованные во внутреннем декоре могилы или в оформлении костяной рукояти парадного кинжала, подчеркивают принадлежность погребения к высшему рангу сарматской элиты. 
Ключевые слова: Нижнее Поволжье, Косика, Боспор, Артюховский курган, Малая Азия, Галатия, Каралар, касты со вставками, клуазонне, изумруды.

Цитирование. Трейстер М. Ю., 2021. Золотые касты со вставками из Косики // Нижневолжский археологический вестник. Т. 20, № 1. С. 153-178. DOI: https://doi.org/10.15688/nav.jvolsu.2021.1.8

\section{Введение}

Я уже рассматривал найденные в погребении сарматского скептуха I в. до н.э. в Косике на Нижней Волге золотые касты, украшенные в технике клуазонне [Treister, 2004a, p. 192, fig. 2,7-9, p. 202; Cat. Rome, 2005, p. 142-143, nos. 97-99; Трейстер, 2007в, с. 291; Мордвинцева, Трейстер, 2007, т. II, с. 42, № A114.9, табл. 78], и касты со вставками изумрудов и стекла разных цветов [Cat. Rome, 2005, p. 146-147, nos. 107-117]. Всего, как было отмечено в первой публикации комплекca, в выбросе из погребения было обнаружено 17 золотых кастов круглой, овальной и ромбической форм с каменными (зеленого, вишневого и охристого цвета) и стеклянными (фиолетового цвета) вставками, а также «каст на ножке со вставкой бирюзы», предполагающие «наличие крупной золотой основы» [Дворниченко, Федоров-Давыдов, 1993, с. 147]. Общее количество кастов, включая «каст на ножке» и три каста со вставками в технике клуазонне, -21 (рис. 1-3).

\section{Касты со вставками в технике клуазонне}

Вначале рассмотрим небольшие бляшки, украшенные клуазонами. Основу бляшек образовывали пластины, к которым напаивались вертикально гнутые полоски, образующие внешние вертикальные края. Напаянные внутри каста торцами полоски образовывали гнезда для вставок из стеклянной массы разных цветов (рис. 1, 2,5-7).

На ромбовидной (рис. 1,3, 2,6) [Дворниченко, Федоров-Давыдов, 1993, с. 144, рис. 3,6, c. 147; Treister, 2004a, p. 193, fig. 2,7, p. 212, no. 19b; Cat. Rome, 2005, p. 143, no. 99; Трейстер, 2007в, с. 291; Мордвинцева, Трейстер, 2007, т. II, с. 42, № A114.9, табл. 78] ${ }^{2}$ и одной из круглых бляшек (рис. 1,2, 2,7) [Дворниченко, Федоров-Давыдов, 1993, с. 144, рис. 3,8, с. 147; Treister, 2004a, p. 193, fig. 2,9, p. 212, no. 19a; Cat. Rome, 2005, p. 142, no. 98; Трейстер, 2007в, с. 291; Мордвинцева, Трейстер, 2007, т. II, с. 42, № A114.9, табл. 78] ${ }^{3}$ представлены композиции в виде розетт из четырех сердцевидных лепестков с остроконечными листками между ними, чрезвычайно близкие мотивам, выполненным в технике клуазонне на щитках булавки (рис. 4) [Отчет..., 1880, с. 8, № 18, с. 55, табл. I,17; Rosenberg, 1921, S. 37, Figs. 51-52; Jacobsthal, 1956, p. 102, 169, fig. 328; Margulies, 1967, p. 781, pl. 248,H; Максимова, 1979, с. 26 (рис.), 49, 50, № 1, примеч. 128; Higgins, 1980, p. 169, 171, pl. 53F; Despini, 1996, p. 183, fig. 177, p. 256; Kat. Bonn, 1997, S. 205-207, Nr. 103; Cat. Amsterdam, 2004, p. 112, fig. 31; Treister, 2004a, p. 190, fig. 1,9, p. 209, no. 3; Трейстер, 2007в, с. 291; Мордвинцева, Трейстер, 2007, т. II, c. 7, № A6.14, табл. 78; Cat. Malibu, 2007 , р. 289, по. 176 ; Власова, 2010, с. 248,249 , рис. 119; Калашник, 2014, с. 254-255] и перстня [Отчет..., 1880 , с. 8 , № 14, с. 52, табл. I,13; Rosenberg, 1921, S. 37, Figs. 49-50; PfeilerLippitz, 1972, S. 113, Taf. 36,11; Максимова, 1979 , с. 65 , 67, № 11, примеч. 212, рис. 19; Higgins, 1980, p. 169, pl. 53D; Despini, 1996, p. 207 , fig. 219 , p. 268 ; Treister, 2004 a, p. 190 , fig. 1,10 , p. 209, no. 4; Трейстер, 2007в, с. 291; Мордвинцева, Трейстер, 2007, т. II, с. 7, № А6.16, табл. 78; Власова, 2010, с. 248, 249, рис. 120] из датирующейся серединой - третьей четвертью II в. до н.э. гробницы I Артюховского кургана. Вставки щитка перстня из Артюховского кургана утрачены, но сравнение со щитком булавки показывает близость двух предметов, отличающихся принципиально лишь набором цветов вставок в клуазоны в форме сердщевидных лепестков ${ }^{4}$. На пластине щитка булавки из Артюховского кургана они выполнены из стеклянной массы зеленоватого, белого и коричневого цвета (рис. 4,2), на бляшке из Косики - вишневого, коричневого, оранжевого и белого (рис. 1,2, 2,7). В остальном форма бляшки, в том числе волнистый профиль ее края (сопоставимый с формой края вставки щитка булавки), явно предполагает, что она могла использоваться изначально в качестве подобной вставки. 
На оборотной стороне бляшки прочерчены две буквы IZ, то есть 17 (если вторая буква - 弓) или 18 (если вторая буква - ๆ). Если таким образом было передано именно число, а не сокращение имени - возможно, это маркировка для сборки, поскольку надпись прочерчена на оборотной стороне каста, которая не была видна на готовом изделии. Аналогий маркировке отдельных элементов ювелирных украшений я не знаю, но хорошо известны буквенные маркировки элементов греческих накладок и ручек бронзовых сосудов еще архаического и классического времени, в частности - на кратерах из Викса [Rolley, 2003, p. 107-112, pls. 85, 105] и Требениште [Василев, 1988, с. 101-103, рис. 82-83; Angelini, 2011, p. 99 , fig. 12 , p. 102, 104, 105, figs. 16-18] и бронзовых ручках сосудов с Афинского акрополя [Tarditi, 2016, p. 21, not. 46, p. 168, nos. 7156, 7130, p. 201, no. 7036, p. 283], а также элементов бронзовых лож позднеэллинистического времени (здесь численные обозначения тремя или четырьмя буквами) [Faust, 1994, S. 588-600, Abb. 26-30, 34-39].

Третья бляшка из Косики, украшенная в технике клуазонне, отличается от них [Дворниченко, Федоров-Давыдов, 1993, с. 144, рис. 3,7 , с. 147 ; Treister, 2004 a, p. 193, fig. 2,8 , p. 212 , no. 19 c; Cat. Rome, 2005 , p. 142 , no. 97 ; Трейстер, 2007в, с. 291; Мордвинцева, Трейстер, 2007, т. II, с. 42, № A114.9, табл. 78] ${ }^{5}$. Ее центральная часть образована двенадцатью узкими сегментами каплевидной и ланцетовидной формы, сгруппированными вокруг маленького центрального гнезда круглой формы. Каждый сегмент, в свою очередь, состоит из клуазонов различной формы и украшен вставками эмали бирюзового, белого и ультрамаринового цвета. Обрамляющий фриз выполнен из чередующихся треугольных и полуовальных клуазонов (рис. 1,1, 2,5).

При рассмотрении возможного происхождения бляшек из Косики следует обратить внимание не только на упомянутые выше ювелирные изделия из гробницы I Артюховского кургана, но и на находку ромбовидного медальона с центральной вставкой в форме четырехлепестковой розетты в Самсуне (древнем Амисе) на южном берегу Черного моря, в настоящее время хранящуюся в Лувре. Следует отметить, что на медальоне из Самсу- на, так же как и на ромбовидной пластине из Косики (рис. 1,3, 2,6), розетта обрамлена тонким кольцом, заполненным белой эмалью, хотя медальон из Самсуна (дл. 2,7 см) крупнее пластины из Косики (дл. 1,7 см) [Rosenberg, 1921, S. 37, Fig. 53; Margulies, 1967, p. 781, pl. 248,F; Higgins, 1980, p. 169; Treister, 2004a, p. 190, fig. 1,8]. Р. Хиггинс не исключал, что подобного рода ювелирные изделия могли изготавливаться в Малой Азии [Higgins, 1980, p. 169].

На оборотной стороне ромбовидной бляшки из Косики (рис. 1,3, 2,6) сохранились смятые три из четырех пластинчатых петель, впаянные в углы, из чего (в том числе и их ориентации) можно предположить, что изначально она могла использоваться в качестве нашивной бляхи или пронизи многорядного ожерелья или крепиться на металлическую пластину, например, диадемы, подобно кастам диадемы из кургана Хохлач (см. ниже). Следы пайки проволочной петли заметны и на оборотной стороне одной из круглых бляшек (рис. $1,2,2,7$ ). О том, что изначально рассматриваемые три бляшки из Косики украшали разные предметы, по крайней мере два разных, свидетельствует тот факт, что бляшка инв. № 35544 (рис. 1,2, 2,7) существенно толще остальных.

\section{Касты со вставками стекла, изумрудов и других драгоценных камней}

Не менее интересны и касты со вставками из Косики (рис. 2-3). Они имеют, как правило, овальную ${ }^{6}$, реже- округлую ${ }^{7}$ или почти ромбовидную ${ }^{8}$ в плане форму (на их фоне выделяется каст в форме столбика, сужающегося на переходе к головке со вставкой ${ }^{9}$ ). Основу их образует пластина соответствующей формы. Вертикальные стенки каста образованы согнутой по периметру полоской, нижний край которой, как правило, завальцован на основание и припаян к нему. Вставка фиксируется в гнезде загнутым верхним краем каста, на уровне которого в верхней части припаяна широкая пластина-кольцо, край которой отогнут вниз. У многих кастов верхняя кромка, фиксирующая вставки, обрезана неровно и не обработана. Касты отличаются не только по форме. Бросаются в глаза два округлых каста очень небрежной работы, у ко- 
торых вертикальные стенки отогнуты внутрь таким образом, что образуют довольно широкую полосу, при этом в одном случае рваные края верхней кромки образуют вырез почти прямоугольной формы, а в другом - почти ромбовидной. В качестве материала для вставок использованы чаще всего стекло различных цветов (8) и изумруд (6), а также гранат (1), альмандин (1), берилл (1), бирюза (1). Есть все основания предполагать, что изначально касты могли относиться к разным предметам.

Касты такой конструкции со вставками из стекла, драгоценных и полудрагоценных камней, в том числе гемм, появляются не позднее II в. до н.э. и используются вплоть до I в. н.э., как правило, для украшения ожерелий, диадем, щитков серег и браслетов [Трейстер, 2007б, с. 276-277, рис. 64,9]. Известны и отдельные находки таких кастов, происходящие как из ограбленных погребений, так и найденные in situ. Обычно их считают элементами ожерелий, как в случае с шестью кастами из комплекса ювелирных украшений, происходящих из Палеокастро в Фессалии, хранящегося в Гамбурге и датируемого в рамках конца II - I в. до н.э. [Hoffmann, von Claer, 1968, S. 38-39, Nr. 27], семью кастами - из погребения в Ногайчинском кургане середины - второй половины I в. до н.э. [Симоненко, 1993, с. 74, № 23 («пуговицы»); Ščepinskij, 1994, S. 105, Nr. 29; Зайцев, Мордвинцева, 2003, c. 73, 74, рис. 8, 12; Mordvintseva, Zaitsev, 2003, p. 212, 213, fig. 8,12; Трейстер, 2007a, с. 65; Мордвинцева, Трейстер, 2007, т. II, с. 53, № A159.11, рис. 18], или диадем, как в случае с шестью кастами из погребения в саркофаге I - начала II в. н.э. в Томах [Kat. Frankfurt. 1994, S. 184-186, Nr. 63.8; Lungu et al., 2012, p. 26 , no. 14 , pls. III, VI]. Особенностью указанных кастов является наличие элементов крепления в форме проволочных петель (двух или четырех), припаянных на оборотной стороне (Палеокастро, Томы), или отверстий в вертикальных стенках каста (Ногайчинский курган) для протягивания нити.

В отличие от рассмотренных выше, касты, найденные в Косике, характеризует не только их значительно большее количество, но и отсутствие петель на обороте или отверстий для протягивания шнура в вертикальных стенках каста. Очевидно, что они использовались не как части ожерелья или диадемы. Я также не вижу никаких оснований для предположения, высказанного авторами первой публикации, о том, что они монтировались на крупной золотой основе [Дворниченко, Федоров-Давыдов, 1993, с. 147]. Касты овальной или прямоугольной формы со вставками граната или разноцветного стекла, использованные в украшении золотых пластин диадемы из кургана Хохлач (четыре - на центральной пластине, четыре и три - на боковых), имели на оборотной стороне припаянные пластинчатые петли, две или четыре, которые вставлялись в прорези на пластинах и фиксировались на оборотной стороне при помощи проволочек [Засецкая, 2011, с. 37-39, № 2, ил. 12-13]. При этом сами касты не были такими высокими, как касты из Косики.

\section{Аналогии из Галатии}

Ближайшими параллелями кастам без петель на оборотной стороне или отверстий для нанизывания в вертикальных стенках каста являются находки [Arik, 1934, p. 121, pl. 19, p. 122, 144; Bingöl, 1999, s. 120, no. 124 (с ошибочной датировкой IV в. до н.э.); Rice, 2016, p. 211, 386; Müller-Karpe, 2018, S. 321-325, Abb. 6-8] из курганов «A» и «С» в Караларе [Arik, 1934, p. 102-167; Arik, Coupry, 1935, p. 133-140; Parachaud, 2015, vol. 1, p. 48-49; Rice, 2016, p. 171-237, 383-387], в Галатии, не так далеко от Анкары (в кургане «В» этой группы была найдена надпись Дейотара II младшего (Филопатора) [Arik, 1934, p. 131; Arik, Coupry, 1935, p. 140-151; Mitchell, 1982, no. 188; Strobel, 2002, S. 256; French, 2003, p. 8283; Coșkun, 2014, S. 143-145; Parachaud, 2015, vol. 1, p. 137-138; vol. 2, p. 88; Rice, 2016, p. 497, fig. 75; Parker, 2018, S. 206; Müller-Karpe, 2018, S. 328, Abb. 2; Regional epigraphic catalogues..., no. 188], погибшего при Филиппах и похороненного здесь ок. 42 г. до н.э.) [Müller-Karpe, 2018, S. 318]. Из 151 предмета ювелирных украшений из Каралара, хранящихся в Музее анатолийских цивилизаций в Анкаре, имеется 17 сохранившихся на сегодняшний день кастов, среди которых есть группа (14) с проволочными петлями (от двух до четырех), припаянными на оборотной стороне [Bingöl, 1999, 
s. 120 , no. 124, верхний ряд, справа и нижний ряд; Müller-Karpe, 2018, S. 323-324, Abb. 6,5$6,9,7,4-5,8,1-12]$, а есть и касты (3) - без таковых [Bingöl, 1999, s . 120, no. 124, верхний ряд, первый и второй - слева; Müller-Karpe, 2018, S. 323, Abb. 7,1-3] (рис. 5). Поскольку погребения, из которых происходят касты, были ограблены, а сами касты из двух комплексов смешаны, трудно сказать, какие именно были найдены в кургане «С», а какие - в кургане «A» [Müller-Karpe, 2018, S. 321-325, Abb. 6-8]. Тем не менее, зная общее количество золотых изделий, найденных в кургане «С» (21 экз.), и то, что отсюда происходит 8 чисто золотых предметов, то есть без вставок, А. Мюллер-Карпе приходит к выводу о том, что из кургана «С» происходит 13 кастов [Müller-Karpe, 2018, S. 323]. Таким образом, на мой взгляд, есть определенные основания предположить, что в кургане «С» были найдены именно касты с петлями, тогда как касты без петель скорее могут происходить из кургана «А».

Недавно А. Мюллер-Карпе предположил, что в кургане «С», откуда, как он указывает, происходит, вероятно, основная часть таких кастов (точно неизвестно, раскопки 1933 г.), были погребены Дейотар I (ок. 120-41/40 гг. до н.э.) и его супруга Береника [Müller-Karpe, 2018 , S. 320]. Это лишь одна из возможных интерпретаций - еще в 1937 г. Ж. Купри предположил, что в кургане «С» мог быть погребен сам Дейотар I по прозвищу Филоромайос [Syme, 1995; Coşkun, 2005; 2013a; Parker, 2018], скончавшийся несколько позже своего сына в 40 г. до н.э. [Coupry, 1937, p. 88] (эту точку зрения поддержали, пусть и в качестве лишь возможной, и другие исследователи [Coşkun, 2014, S. 144]). Именно в сражении с Дейотаром в ходе своего малоазийского похода 47 г. до н.э. Фарнак II Боспорский, в составе войска которого, как я предположил ранее, был и скептух, погребенный в Косике [Трейстер, 2005, c. 322-330; Treister, 2005, p. 223-240], захватил принадлежавшую ему Малую Армению. Очевидно, однако, что все три кургана связаны между собой и курган «С» также датируется не позднее I в. до н.э. [Rice, 2016, p. 193-194, 236], при этом самым ранним в этой группе является курган «А», который на основании найденных в нем немногочислен- ных предметов, в частности фибулы [Arik, 1934, p. 122, pl. 9, fig. 18; Caner, 1983, S. 152153, Nr. 1064, Taf. 60; Strobel, 2002, S. 260, Anm. 82; Rice, 2016, p. 185-186, fig. 64] и унгвентария [Arik, 1934, p. 119, 122-123, pl. 13, fig. 19a; Rice, 2016, p. 186-189, 492, fig. 66], может датироваться еще концом II - началом I в. до н.э. [Rice, 2016, p. 189]. Теоретически такой хронологический разрыв между погребениями в кургане «А», с одной стороны, и курганах «B» и «С»- с другой, действительно, мог бы объясняться тем, что в кургане «А» был погребен отец Дейотара I - Синорикс, о котором сообщается в надписи на базе статуи, воздвигнутой афинянами в честь Дейотара [Dittenberger (ed.), 1882, no. 3429; Strobel, 2002, S. 240; Hofeneder, 2004, S. 707, Anm. 11; Coşkun, 2013b, S. 156, Anm. 17; Parker, 2018, S. 191, Anm. 12; Spickermann, 2006].

Ошибка во французском переводе написанной по-турецки части совместной статьи Арика и Купри, опубликованной в «Revue Archéologique» в 1935 г. [Arik, Coupry, 1935, p. 140], привела к тому, что долгое время считалось, что в кургане «А» были найдены части золотой гривны со вставками драгоценных камней. Между тем в опубликованном на турецком языке полном отчете о раскопках речь шла о том, что эти вставки, возможно, относились к диадеме или ожерелью [Arik, 1934, p. 144]. На эту неточность уже обращали внимание [Coşkun, 2014, S. 144-145; Müller-Karpe, 2018, S. 324, Anm. 44].

А. Мюллер-Карпе указал на три каста без петель из Каралара и высказал, на мой взгляд, совершенно справедливое предположение о том, что они не могли являться элементами нательных украшений [Müller-Karpe, 2018, S. 323]. Это высокие овальные касты разных размеров со вставками, которые исследователь предположительно определяет как изумруд, хризопраз и аметист [MüllerKarpe, 2018, S. 323, Abb. 7,1-3]. При общей высоте кастов 0,40-0,45 см, судя по фотографии с масштабом, их нижняя часть с вертикальными стенками, то есть часть каста ниже горизонтального «воротничка», составляет 0,20-0,25 см. Соответственно, эти касты должны были быть впущены в основание на такую глубину. Исследователь предполагает, что касты изначально могли украшать стены 
погребальной камеры, вероятнее всего оштукатуренные и, возможно, обтянутые пурпурными тканями [Müller-Karpe, 2018, S. 323-325]. Подобным образом драгоценные камни в бронзовых позолоченных кастах использовались в архитектурном декоре в Риме в императорскую эпоху [Zinc, 2019 , p. 28, fig. 26].

\section{Касты со вставками изумруда или берилла в ювелирных изделиях эпохи позднего эллинизма и ранней Империи}

Касты из Косики, по сравнению с рассмотренными кастами из Каралара, имеют различную высоту. Как и среди кастов из Каралара, значительное количество кастов украшены вставками зеленого цвета из изумруда и берилла. Вставки из этих камней начинают использоваться еще во II в. до н.э., в частности ромбовидный каст со вставкой изумруда или берилла украшает ожерелье из гробницы I Артюховского кургана [Отчет..., 1880, c. 7, № 6, 49, табл. I,6; Ruxer, Kubszak, 1972, p. 26, 183, pl. V,1; Максимова, 1979, с. 29, рис. 57, № 5, примеч. 162; Higgins, 1980, pl. 50A; Pfrommer, 1990, S. 92, 262, 328, Nr. TK 106; Despini, 1996, p. 177, fig. 168, p. 253-254; Kat. Bonn, 1997, S. 204-205, Nr. 102; Калашник, 2004, с. 103 , рис. 6; 2014, с. 246-247 (берилл); Treister, 2004b, p. 232-235, no. 3, fig. 3; 2006 , p. 520, no. 1, fig. 1; Мордвинцева, Трейстер, 2007, т. II, с. 7, № А6.7 с лит., табл. 21; Cat. Malibu, 2007, p. 288, no. 175 (здесь - изумруд)]. Аналогичный по форме каст, также со вставкой изумруда, происходит из материалов кораблекрушения у расположенного между Пелопоннесом и северо-западным побережьем Крита о. Антикитира [Stassinopoulou, 2012, p. 147, no. 116]. Комплекс находок различных категорий, в том числе амфоры с клеймами (Родос, Эфес, Кос) [Kourkoumelis, 2012, p. 211] и монеты [Tselekas, 2012, p. 218], датируют кораблекрушение временем не позднее середины I в. до н.э., с большой долей вероятности (по монетам) 70-60-ми гг. до н.э. Из этого же комплекса происходит пара серег со щитками, украшенными вставками в кастах, жемчужинами и подвесками - центральные вставки щитков - изумрудные [Jackson, 2010, p. 181-182, figs. $2, a, b, 3$, p. 192; Stassinopoulou, 2012, p. 149-150, no. 119]. Близкая к квадратной (ромбовидной) форме вставка хризопраза, наряду со вставками из этого же материала в трех других кастах, обрамляет центральный медальон ожерелья из погребения в кургане № 10/1979 у хут. Песчаный [Анфимов, 1987 , с. 205 ; 2011, с. 211; Ждановский, 1990 , c. 105-106, рис. 35; Delivorrias, 1999, p. 236, fig. 169; Cat. Paris, 2001, p. 171, no. 181 (хризопраз); Treister, 2004b, p. 232-235, no. 3, fig. 3; 2006 , p. 520, no. 3, fig. 2; Трейстер, 2007a, с. $63-$ 65; Мордвинцева, Трейстер, 2007, т. II, с. 71, № A227.4 с лит., табл. 1, 37; Marčenko, Limberis, 2008, S. 338, Nr. 12.2 (берилл), Taf. 18,2; Мордвинцева и др., 2010, с. 313, № 407, рис. 30, табл. 72, цв. табл. 7], датируемого около середины I в. до н.э. [Ждановский, 1990, с. 105-114; Cat. Paris, 2001, p. 168177] (отметим находку в этом погребении чаши мозаичного стекла [Лимберис, Марченко, 2003 , с. 111,119 , № 8, рис. 17; Marčenko, Limberis, 2008, S. 300, 339, Nr. 12.6, Taf. 19,2], находящую аналогии и в кораблекрушении у о. Антикитира, и на Делосе [Nenna, 1999, p. 46-47, nos. B 74-82, pl. 3]).

Пластины с прямоугольными кастами со вставками из изумруда (?) - щитки серег с головками рыси из клада, обнаруженного на о. Делос в 1964 г. [Hackens, Lévy, 1965, p. 548552, no. IV, pl. XXI; Pfeiler-Lippitz, 1972, S. 111112; Zafeiropoulou, 1998, p. 295, no. 257; Hadjidakis, 2003, p. 241, no. 353, p. 431]. Этот клад, найденный «в квартале ювелиров» и состоящий из ювелирных изделий и монет, достаточно надежно датируется или ок. 122, или 88 г. до н.э. [Hackens, Lévy, 1965, p. 533-534]. Прямоугольные касты со вставками изумруда украшают пластинчатые золотые браслеты, которые были найдены в саркофаге в аристократической гробнице в Кочакизларе (в районе Эскишехира в Малой Азии), датирующейся в рамках I в. до н.э. - начала I в. н.э. [Atasoy, 1974, p. 261, 262, no. 18, pl. 52,5]. Прямоугольная вставка изумруда украшает и щиток одного из найденных здесь перстней [Atasoy, 1974, p. 261, 262, no. 9]. Подобной формы касты со вставками изумруда оформляют и щитки серег с подвесками в виде фигурок эротов, хранящиеся в Музее Бенаки и датируемые II-I вв. до н.э. [Segall, 1938, S. 55- 
56, Nr. 43, Taf. 16a; Delivorrias, 1999, p. 230 231 , no. 81, fig. 165; Jackson, 2010, p. 188-189, fig. 8; 2017, p. 79, fig. 15a, p. 141-142, no. 71].

Отметим, что во всех этих случаях сами касты со вставками изумруда имеют другую конструкцию, самую простую, без воротничка [Трейстер, 2007б, с. 272-273, тип 1, рис. 64,1$]$. Вставка фиксируется отогнутым внутрь вертикальным краем каста. Лишь упомянутые выше касты ожерелья из Песчаного имеют конструкцию, близкую кастам из Косики и Каралара.

Прямоугольные и овальные вставки изумрудов украшают и браслеты с известным местом происхождения, но с неизвестными обстоятельствами и, соответственно, контекстами - их по стилистическим особенностям датируют I в. н.э., как элементы браслета из Пирея в собрании Музея Бенаки [Segall, 1938, S. 81-82, Nr. 93, Abb. 27; Pfeiler, 1970, S. 47, Abb. 6-7; Cat. Dallas, 1990, p. 64, fig. 44; Delivorrias, 1999, p. 252, no. 92, fig. 180], или I в. до н.э., как пару браслетов, происходящих из Ольвии - в собрании Музея изящных искусств в Бостоне [Deppert-Lippitz, 1985, S. 294, Taf. XXXII; Delivorrias, 1999, p. 253, fig. 181; Cat. New York, 2016, p. 238-239, no. 177]. Другие примеры вставок из изумрудов и подражавшего им стекла зеленого цвета в прямоугольных кастах в ювелирных изделиях позднеэллинистического и раннеимператорского времени уже приводились мною [Treister, 2002, p. 33, notes $58-60]$.

Плиний Старший (NH XXXVII, 15-20) отмечал, что после алмазов и жемчуга изумруды были наиболее ценными камнями в древности, сообщая также о том, что Александр Македонский запрещал всем, кроме Пирготеля, гравировать свой портрет на изумруде (NH XXXVII, 4) [Krug, 1987, S. 467-471; Gagetti, 2006, p. 57-59; Zwierlein-Diehl, 2007, S. 309; Platz-Horster, 2010, p. 187-188], а Плутарх (Лукулл, 3.1) приводит историю, когда царь Птолемей II Сотер в 85 г. до н.э. преподнес Лукуллу «оправленный в золото смарагд огромной цены» [Plantzos, 1999, p. 111]. Считается, что изумруды начали разрабатываться Птолемеями и египетские залежи изумрудов были одним из двух источников изумрудов для Европы и Африки. Страбон (17.1.45) упоминает добычу изумрудов в юго-западной пус- тыне Египта в 24 г. до н.э. [Shaw et al., 1999, p. 203, 205].

\section{Особенности кастов из Косики и их возможное использование}

Если оставить вне поля зрения каст в виде столбика со вставкой бирюзы высотой 1,4 см, явно отличающийся от всех остальных, то общая высота кастов колеблется от 0,29 до 0,72 см, при этом она не всегда коррелирует с размерами самих кастов (так, самыми высокими, 0,70-0,72 см, являются касты со вставками изумруда инв. № 35547-35548, размеры которых $1,1 \times 0,92$ и $0,88 \times 0,68 \mathrm{~cm}$ (рис. $2,8,10)$ ), хотя в целом чем каст крупнее, тем он выше. Глубина кастов ниже «воротничка» колеблется между 0,22 и 0,40 см. Тем самым очевидно, что именно на такую глубину (до 0,4 см) касты были впущены в основу, при этом края «воротничков» были сдвинуты вниз, что обеспечивало их фиксацию, при этом нельзя исключать, что они также были вклеены в основу. Каст в форме столбика со вставкой бирюзы инв. № 45633, судя по его конфигурации, мог быть заглублен на $0,8 \mathrm{~cm}$ (до перехода) к узкой части, отделяющей головку со вставкой от нижней части каста (рис. 2,4$)^{10}$. Соответственно, возникает вопpoc: из какого материала могла быть выполнена основа? Мы уже исключили возможность металлической (золотой) основы. Судя по глубине впуска кастов, это вряд ли могла быть основа из ткани или кожи, скорее всего - деревянная или костяная.

Можно предположить, что касты могли украшать деревянные конструкции, на которых крепился расшитый золотыми бляшками и нитями погребальный полог. К этой конструкции могли относиться два выточенных на станке деревянных круглых столбика диаметром ок. 5,0-5,5 см, один из которых сохранился на длину ок. 50 см, с профилированными серебряными обкладками на концах [Дворниченко, Федоров-Давыдов, 1993, с. 143-145, рис. 3,5].

Каст инв. № 45633 (рис. 2,4) мог использоваться в качестве крючка, вешалки, хотя нельзя исключать, что он мог выполнять функцию шпенька пряжки, подобно украшенным шпенькам фигурных пряжки и наконечника 
ремня из Косики [Трейстер, 2018, с. 113, рис. $1,1,2,1,3,1,3,4,1,8]$ (круглый и каплевидный касты).

Находку из Косики и близкую ей пряжку из Сибирской коллекции [Rudenko, 1962, S. 15, 50, Taf. II,4; Штейн, 1968; Артамонов, 1973, с. 165 , рис. 217 ; Мордвинцева, 2003, с. $84-85$, № 34, рис. 13; Трейстер, 2018, с. 112 с лит.] сближает оформление шпенька каплевидным кастом со вставкой (бирюзы - на пряжке из Сибирской коллекции, граната - на пряжке из Косики). Подобным же каплевидным кастом, также со вставкой бирюзы, оформлен шпенек одной из двух золотых поясных пластин, найденных в Сидоровке [Матющенко, Татаурова, 1997, с. 48 , рис. 27,2; Koryakova, 2006, p. 108 , fig. 9,1 ; Brosseder, 2011, p. 375, 376, fig. 24,13]. Инкрустированные шпеньки со вставками каплевидной формы имелись также у золотых пряжек I в. до н.э. - I в. н.э. из Дальверзин-Тепе (вставка утрачена) [Pougatchenkova, 1978, p. 102, fig. 80; Мордвинцева, 2003, с. 56, рис. 43,7; Abdullaev, 2008, p. 138, fig. 3], Нихавенда (вставка бирюзы на пряжке, хранящейся в Нью-Йорке [Ghirshman, 1962, p. 100, fig. 112 (вверху); Cat. New York, 2000, p. 124-125, no. 95, p. 208]), погребения IV некрополя Тилля-Тепе (бирюза) [Sarianidi, 1985, S. 182-183, Taf. 124, S. 246, Nr. 4.1; Mopдвинцева, 2003, с. 21, 83, № 11, рис. 5; Kat. Bonn, 2010, S. 195, 197, Nr. 106; Трейстер, 2018 , с. 112 с лит.] и у серебряной пряжки из погребения № 2 кургана № 20/1982 могильника у хут. Новый (стекло темно-коричневого цвета) [Трейстер, 2018, с. 111, рис. 7].

Округлые вставки на шпеньке, как у наконечника пояса из Косики, имеются на пряжках из погребения кургана № 12/1965 у с. Никольского (вставка из стекла) [Засецкая, 1979, c. 111 , рис. 22 ; Мордвинцева, 2003, с. 42,88 , № 58, рис. 22; Мордвинцева, Трейстер, 2007, т. II, с. 49, № A146.2, рис. 33, табл. 32; Brosseder, 2011, p. 398-401, fig. 47,2, p. 421, list 5, nо. 2; Трейстер, 2018, с. 113 с лит., рис. 8] и Порогов (бирюза) [Симоненко, Лобай, 1991, c. 14-18, № 7a-b, рис. 8-9, табл. 11-12; Мордвинцева, 2003, с. 40, 43, 51, 73, 78, 95, № 107, рис. 40; Мордвинцева, Трейстер, 2007, т. II, c. 73, № A234.7, табл. 38, рис. 50; Brosseder, 2011, p. 401, 403, fig. 50,29-30, p. 424, list 9, nо. 7; Трейстер, 2018, с. 113 с лит.].
Из рассматриваемого погребения в Косике происходит и костяная пряжка с рельефным изображением совы: в два отверстия на конце ее вставлены золотые заклепки, а в отверстие спереди на рамке - золотой шпенек, по форме близкий рассматриваемому, но без каста со вставкой [Дворниченко, ФедоровДавыдов, 1993, с. 175, рис. 20,2, с. 176; Трейстер, 2018, с. 113-114, рис. 11].

Другой вариант - украшение кастами или частью из них, например кастами в технике клуазонне, утраченной костяной рукояти найденного в погребении парадного кинжала в ножнах с греческой надписью на перекрестье, датированной по селевкидской эре, который был изготовлен в Малой Азии, возможно - в Коммагене, в 74 г. до н.э. [Белоусов, Трейстер, 2018; Belousov, Treister, 2020]. О том, что рукоять имела изначально костяные обкладки, свидетельствует слой кости, сохранившейся на перекрестье между железной основой рукояти и золотым листом обкладки перекрестья. Подобным образом золотым кастом со вставкой альмандина была украшена деревянная обкладка рукояти меча из позднеантичного погребения некрополя Фанагории [Трейстер, 2015 a, с. 174,175 , рис. 42,2 , с. 177 ; 20156 , c. 504, № 191, с. 506-507, табл. 64-65].

\section{Заключение}

Проведенный анализ показал, что золотые касты со вставками из Косики имеют различное происхождение и некоторые их них могли изначально использоваться в украшениях ожерелий или щитков булавок. Это касается в первую очередь кастов со вставками в технике клуазонне, которые могут датироваться еще II в. до н.э. Анализ других кастов со вставками из стекла и драгоценных камней, преимущественно изумрудов, вполне подтверждает возможность их датировки в рамках конца II - середины I в. до н.э. Отмечается близость этих кастов находкам из царских галатских гробниц этого времени в Каралаpe - не исключено, что касты без петель на оборотной стороне происходят из самой ранней гробницы «А», в которой, возможно, был погребен отец Дейотара I - Синорикс. Безусловно, невозможно говорить о какой-то прямой связи между использованием золотых 
кастов со вставками в гробнице царя Галатии и сарматского вождя, тем не менее, учитывая чрезвычайную редкость таких предметов и их хронологическую близость, нельзя не обратить внимание на малоазийскую параллель кастов из Косики.

Наряду с другими уникальными предметами из погребения на Нижней Волге [Дворниченко, Федоров-Давыдов, 1989; 1993; Dvornitchenko, Fedorov-Davydov, 1994; Treister, 1997, p. 49-74] золотые касты со вставками, вероятнее всего использованные во внутреннем декоре могилы (подобно тому, как золотыми бляхами с изображениями Ахурамазды был, вероятнее всего, оформлен вход в погребальную камеру погребения № 1 царского кургана могильника Филипповка-І в Южном Приуралье [Трейстер, 2012, с. 139-140, табл. I.37-39, табл. I.114-115, II.10, 1.3, рис. I.82, II.62,6-8]) или в оформлении костяной рукояти парадного кинжала, подчеркивают принадлежность погребения к высшему рангу сарматской элиты. Об этом же свидетельствуют и другие происходящие из погребения предметы, в том числе антикварные: переднеазиатские цилиндрические печати середины II и середины I тысячелетия до н.э. [Клочков, 1994; Klochkov, 1996; Трейстер, 2019, c. 23-26, рис. 2-3; 2020а]; выполненная в архаическом греко-скифском стиле и переделанная в начале IV в. до н.э. золотая пектораль со сценами терзания [Трейстер, 2020б]; упомянутый выше парадный кинжал в ножнах с греческой надписью [Белоусов, Трейстер, 2018; Belousov, Treister, 2020]; серебряный с позолотой и гравированными фигурными изображениями столовый сервиз, в том числе таз с надписью царя Артевазда, возможно Артевазда II, царя Армении, правившего в 55-34 гг. до н.э. [Трейстер, 1994; 2005; Treister, 2005, p. 223-240]; парадный пояс с уникальными фигурными пряжкой и наконечником ремня с потайными отделениями [Трейстер, 2018].

\section{ПРИМЕЧАНИЯ}

${ }^{1}$ Представленная публикация выполнена в рамках проекта, финансируемого DFG и РГНФ, «Формы и пути культурных контактов кочевников Азиатской Сарматии. Импорты в сарматских памятниках II в. до н.э. - III в. н.э.» (FL-334/15-1). Партнер проекта с российской стороны - Б.А. Раев. Автор выражает искреннюю признательность за предоставленную нам возможность работать в фондах Астраханского государственного объединенного историко-архитектурного музея-заповедника, в которых хранятся рассмотренные в статье касты со вставками, хранителю Э.Р. Чиняковой.

The present publication was made in frames of the project funded by the DFG (German Science Foundation) and the Russian Humanitarian Scientific Foundation "Forms and ways of cultural contacts of the nomads of Asian Sarmatia. Imports in the Sarmatian monuments of the $2^{\text {nd }}$ century BC $-3^{\text {rd }}$ century AD" (FL-334/15-1). The project partner from the Russian side - B.A. Raev. The author expresses his sincere gratitude for the opportunity given to us to work in the depots of Astrakhan State United Historical and Architectural Museum-Reserve, in which the settings discussed in the article are kept: to the curator E.R. Chinyakova.

${ }^{2}$ Астрахань, Астраханский государственный объединенный историко-архитектурный музей-заповедник, инв. № 35543. Дл. 1,7 см, шир. 1,1 см, толщ. 0,29 см, шир. полоски петли 0,1 см. Вес 0,92 г. Проба 930.

${ }^{3}$ Астрахань, Астраханский государственный объединенный историко-архитектурный музей-заповедник, инв. № 35542. Дм. 1,0 см, толщ. 0,3 см. Вес 1,26 г. Проба 960.

${ }^{4} \mathrm{~K}$ сожалению, ни в одной из многочисленных эрмитажных публикаций не указывается размер щитка булавки, нет масштаба, а приводимые размеры булавки указывают лишь ее длину: в одном случае - 7,7 см [Максимова, 1979, с. 49, примеч. 128], в другом - 15 см [Калашник, 2014, с. 254]. Вызывает сожаление, что в крупнейшем музее России до сих пор измеряют ювелирные украшения с точностью до 1 см (!) Если предположить, что М.И. Максимова приводила длину самой булавки, а Ю.П. Калашник - булавки, щитка и подвесок вместе, тогда, если мы исходим из длины 7,7 см самой булавки, круглая вставка щитка имеет диаметр ок. 0,95-0,96 см, что почти точно соответствует диаметру бляшки из Косики.

${ }^{5}$ Астрахань, Астраханский государственный объединенный историко-архитектурный музей-заповедник, инв. № 35544. Дм. 1,1 см, толщ. 0,41 см. Вес 1,36 г. Проба 950.

${ }^{6}$ Астрахань, Астраханский государственный объединенный историко-архитектурный музей-заповедник. 1) Инв. № 35545. 1,2 × 0,9 см, в. 0,7 см. Вес 1,33 г. Проба 950. Альмандин (рис. 3,10); 2) Инв. № 35546. 1,36 × 1,0 см, в. 0,57 см. Вес 1,59 г. Проба 950. Желтое полупрозрачное стекло (рис. 3,7); 3) инв. № 35547. 0,88 ×0,68 см, в. 0,7 cм. Вес 0,84 г. Проба 950. Изумруд 1,10 карата (рис. 2,10); 
4) Инв. № 35548. 1,1 × 0,92 см, в. 0,72 см. Вес 0,75 г. Проба 950. Изумруд 0,90 карата (рис. 2,8); 5) Инв. № $39216.1,35 \times 1,2$ см, в. 0,56 см. Вес 1,01 г. Проба 850. Темно-коричневое стекло; 6) Инв. № 45638. $0,98 \times 0,88$ см, в. 0,35 см. Вес 0,41 г. Проба 820. Гранат (рис. 3,2); 7) Инв. № 45639. 0,63 ×0,53 см, в. 0,33 см. Вес 0,17 г. Проба 910. Изумруд 0,50 карата (рис. 2,2); 8) Инв. № 35549. 1,2 × 0,99 см, в. 0,4 см. Вес 0,66 г. Проба 920. Темно-коричневое стекло (рис. 3,8); 9) Инв. № 45634. 1,3 × 1,0 см, в. 0,5 см. Вес 0,84. Проба не известна. Фиолетовое стекло (рис. 3,5); 10) Инв. № 45635. 1,3 × 1,0 см, в. 0,33 см. Вес и проба не известны. Стекло, цвет не определяется (рис. 3,4$)$.

${ }^{7}$ Астрахань, Астраханский государственный объединенный историко-архитектурный музей-заповедник. 1) Инв. № 45640. Дм. 0,63 см, в. 0,29 см. Вес 0,20. Проба 910. Берилл (рис. 2,3); 2) Инв. № 35550. Дм. 1,26 см, в. 0,44 см. Вес и проба не известны, вставка утрачена (рис. 3, б); 3) Инв. № 39215. Дм. 1,1 см, в. 0,42 см. Вес 0,8 г. Проба 583. Зеленое полупрозрачное стекло (рис. 3,1); 4) Инв. № 39217. Дм. 1,0 см, в. 0,5 см. Вес 0,71 г. Проба 600. Зеленое полупрозрачное стекло (рис. 3,3); 5) Инв. № 45637. $0,5 \times 0,45$ см, в. 0,39 см. Вес 0,26 г. Проба 950. Изумруд 0,30 карата (рис. 2,1 ).

${ }^{8}$ Астрахань, Астраханский государственный объединенный историко-архитектурный музей-заповедник. 1) Инв. № 35551. 0,95 × 0,82 cм, в. 0,46 cм. Bec 0,62 г. Проба 800. Изумруд 1,10 карата (рис. 2,9); 2) Инв. № 45636. 1,0 × 0,94 cм, в. 0,67 cм. Вес 1,01 г. Проба 950. Изумруд 1,20 карата (рис. 2,11).

${ }^{9}$ Астрахань, Астраханский государственный объединенный историко-архитектурный музей-заповедник. Инв. № 45633. В. 1,4 см, дм. каста $0,59 \times 0,64$ см, ДМ. нижнего основания ножки 0,45 см. Вес 3,04 г. Проба 916. Бирюза (рис. 2,4).

${ }^{10}$ Астрахань, Астраханский государственный объединенный историко-архитектурный музей-заповедник. Инв. № 45633. В. 1,4 см, дм. каста $0,59 \times 0,64$ см, дм. нижнего основания ножки $0,45 \mathrm{~cm}$. Bec 3,04 г. Проба 916. Бирюза. 


\section{ИЛЛЮСТРАЦИИ}
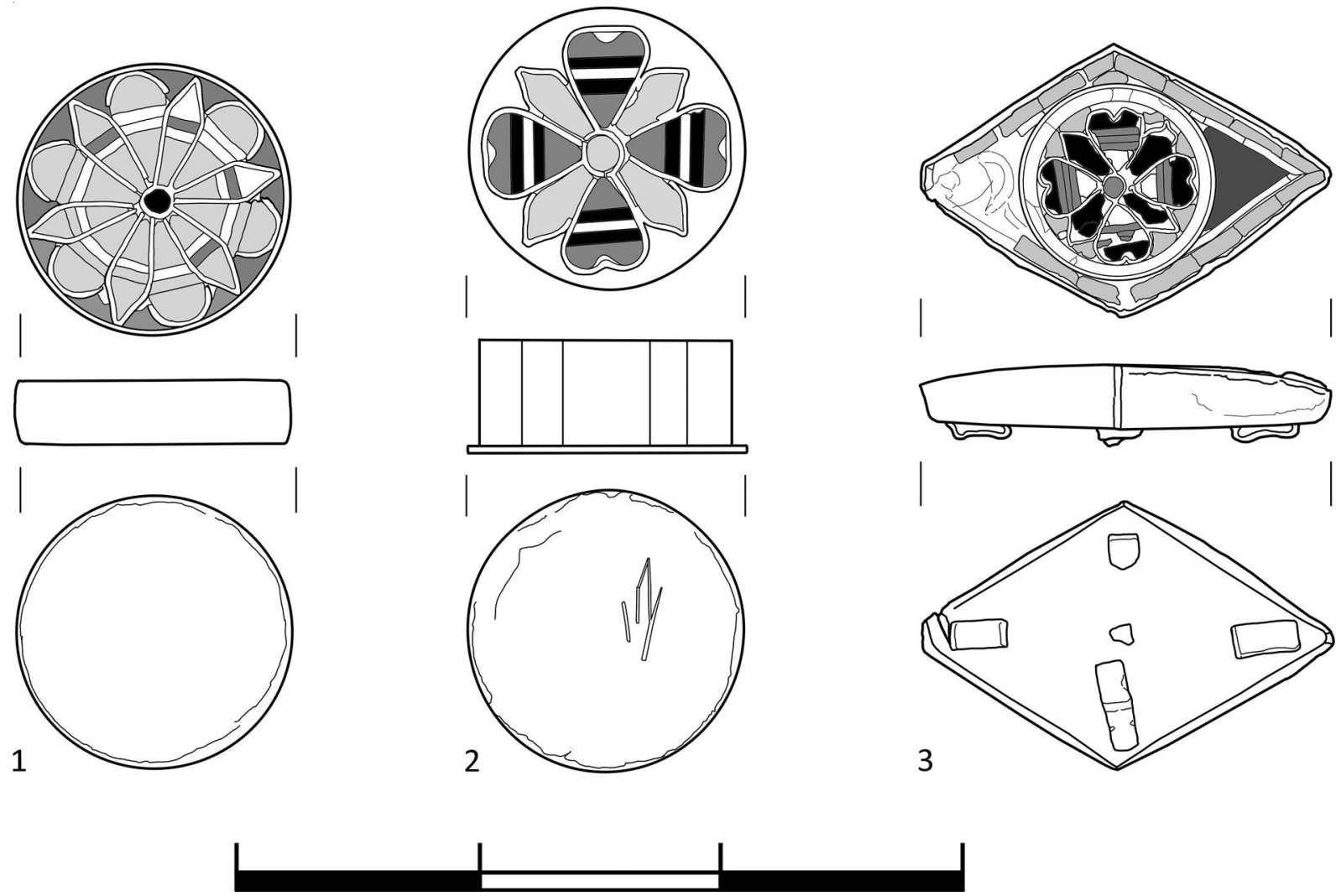

Рис. 1. Косика. Погребение № 1/1984. Золотые касты со вставками в технике клуазонне (Астрахань, Астраханский государственный объединенный историко-архитектурный музей-заповедник).

Рис. Н.Е. Беспалой, 2015:

1 - инв. № 35542; 2 - инв. № 35544; 3 - инв. № 35543

Fig. 1. Kosika. Burial no. 1/1984. Gold settings with inlays in the cloisonné technique (Astrakhan, Astrakhan State United Historical-Architectural Museum-Reserve).

Drawings by N.E. Bespalaya, 2015:

1 - inv. no. $35542 ; 2$ - inv. no. $35544 ; 3$ - inv. no. 35543 
M.Yu. Treister. Gold Settings with Inlays from Kosika
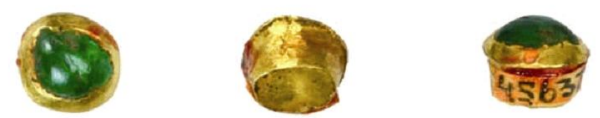

1
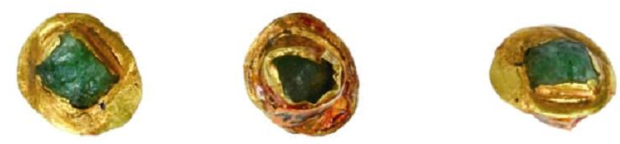

2
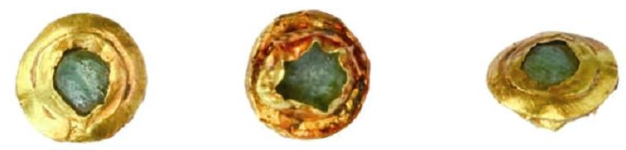

3
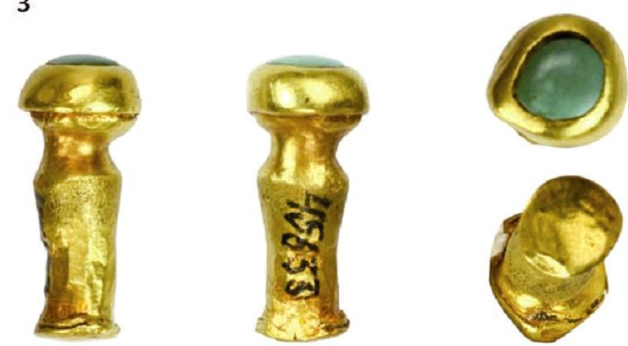

6
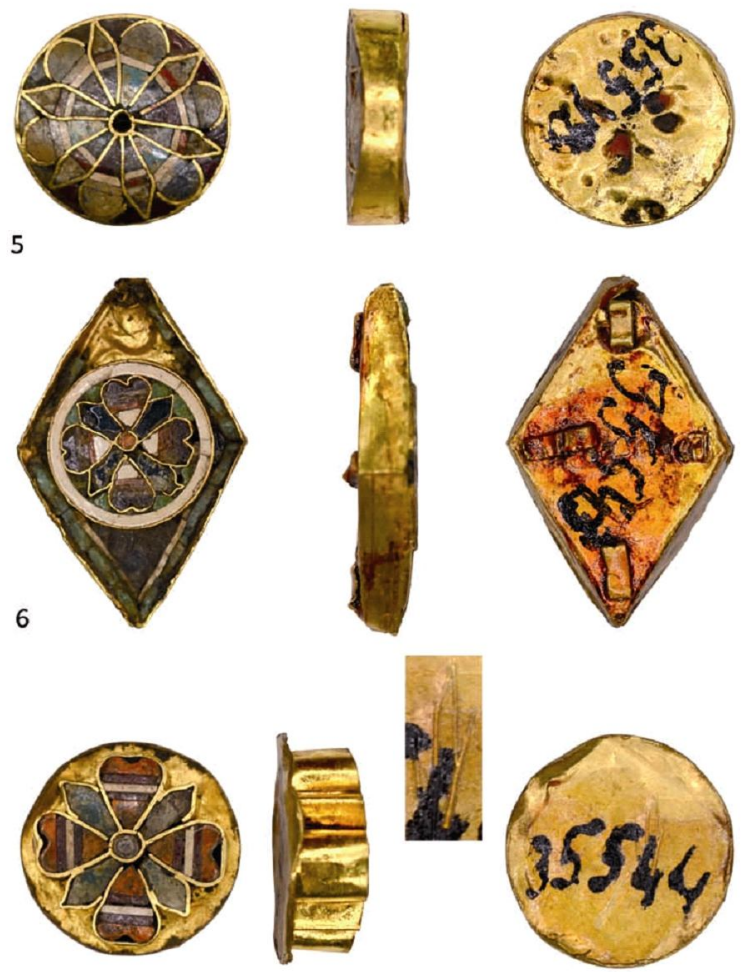

4
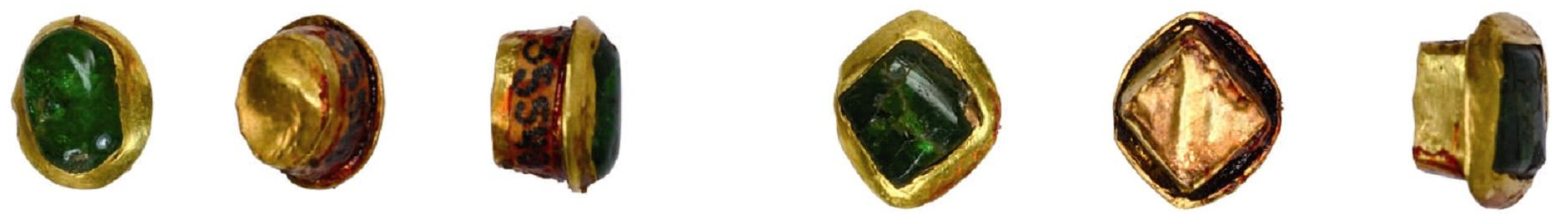

8
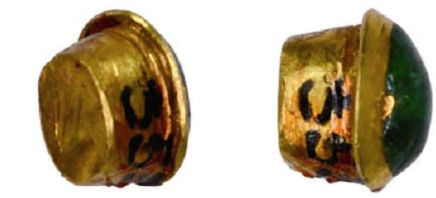

10

9
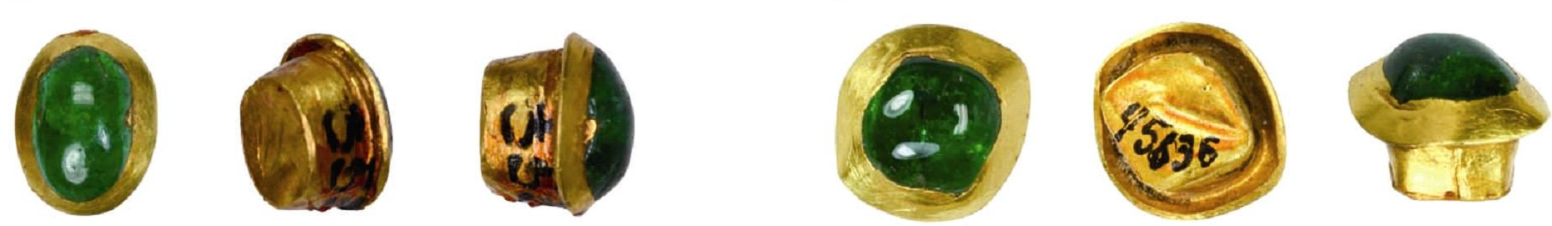

11

Рис. 2. Косика. Погребение № 1/1984. Золотые касты со вставками

(Астрахань, Астраханский государственный объединенный историко-архитектурный музей-заповедник). Фото М.Ю. Трейстера, 2015:

1 - инв. № 45637; 2 - инв. № 45639; 3 - инв. № 45640; 4 - инв. № 45633; 5 - инв. № 35542; 6 - инв. № 35543; 7 - инв. № 35544; 8 - инв. № 35548; 9 - инв. № 35551; 10 - инв. № 35547; 11 - инв. № 45636

Fig. 2. Kosika. Burial no. 1/1984. Gold settings with inlays

(Astrakhan, Astrakhan State United Historical-Architectural Museum-Reserve). Photos by M. Treister, 2015 :

1 - inv. no. $45637 ; 2$ - inv. no. 45639; 3 - inv. no. 45640; 4 - inv. no. $45633 ; 5$ - inv. no. 35542; 6 - inv. no. 35543 ; 7 - inv. no. $35544 ; 8$ - inv. no. 35548; 9 - inv. no. $35551 ; 10$ - inv. no. $35547 ; 11$ - inv. no. 45636 


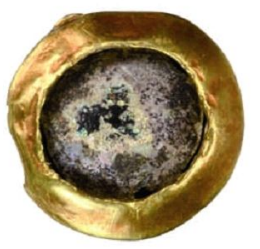

1
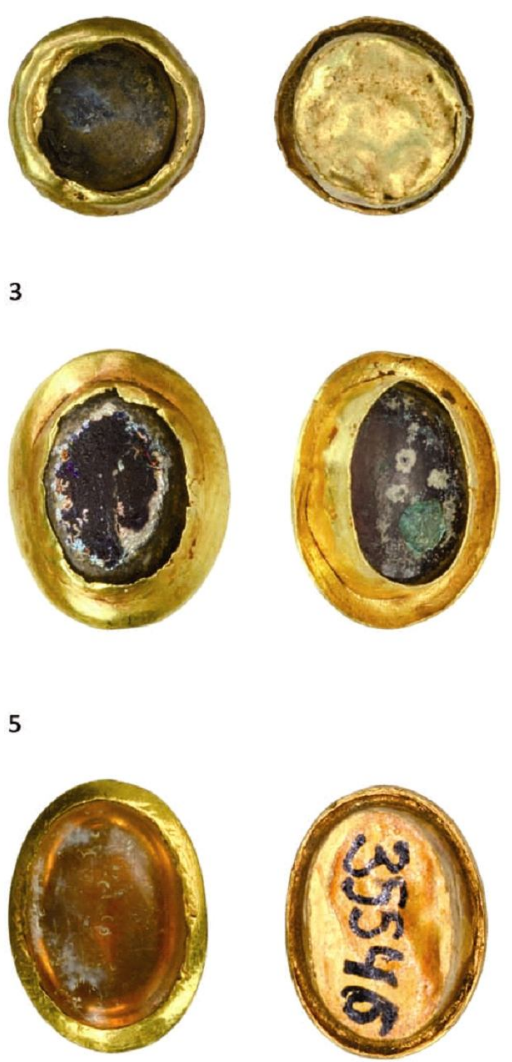

7

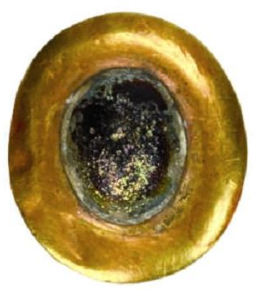

9
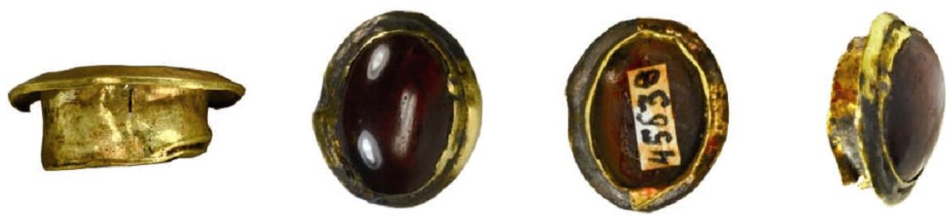

2
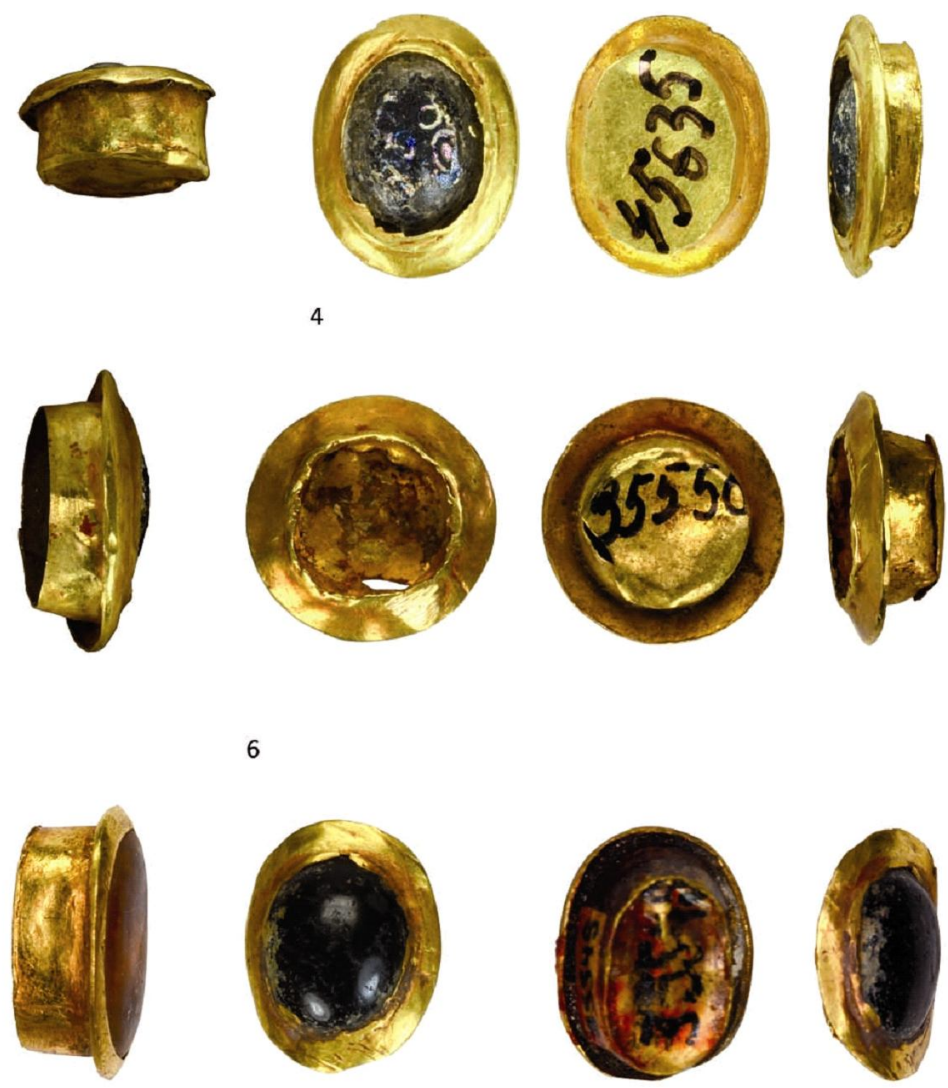

8
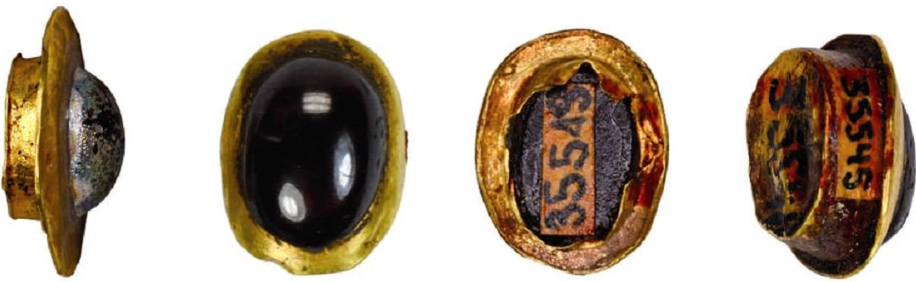

10

Рис. 3. Косика. Погребение № 1/1984. Золотые касты со вставками (Астрахань, Астраханский государственный объединенный историко-архитектурный музей-заповедник). Фото М.Ю. Трейстера, 2015:

1 - инв. № 39215; 2 - инв. № 45638; 3 - инв. № 39217; 4 - инв. № 45635; 5 - инв. № 45634; 6 - инв. № 35550;

$$
7 \text { - инв. № 35546; } 8 \text { - инв. № 35549; } 9 \text { - инв. № 39216; } 10 \text { - инв. № } 35545
$$

Fig. 3. Kosika. Burial no. 1/1984. Gold settings with inlays.

(Astrakhan, Astrakhan State United Historical-Architectural Museum-Reserve). Photos by M. Treister, 2015:

1 - inv. no. 39215; 2 - inv. no. 45638; 3 - inv. no. 39217; 4 - inv. no. 45635; 5 - inv. no. 45634; 6 - inv. no. 35550; 7 - inv. no. $35546 ; 8$ - inv. no. $35549 ; 9$ - inv. no. $39216 ; 10$ - inv. no. 35545 


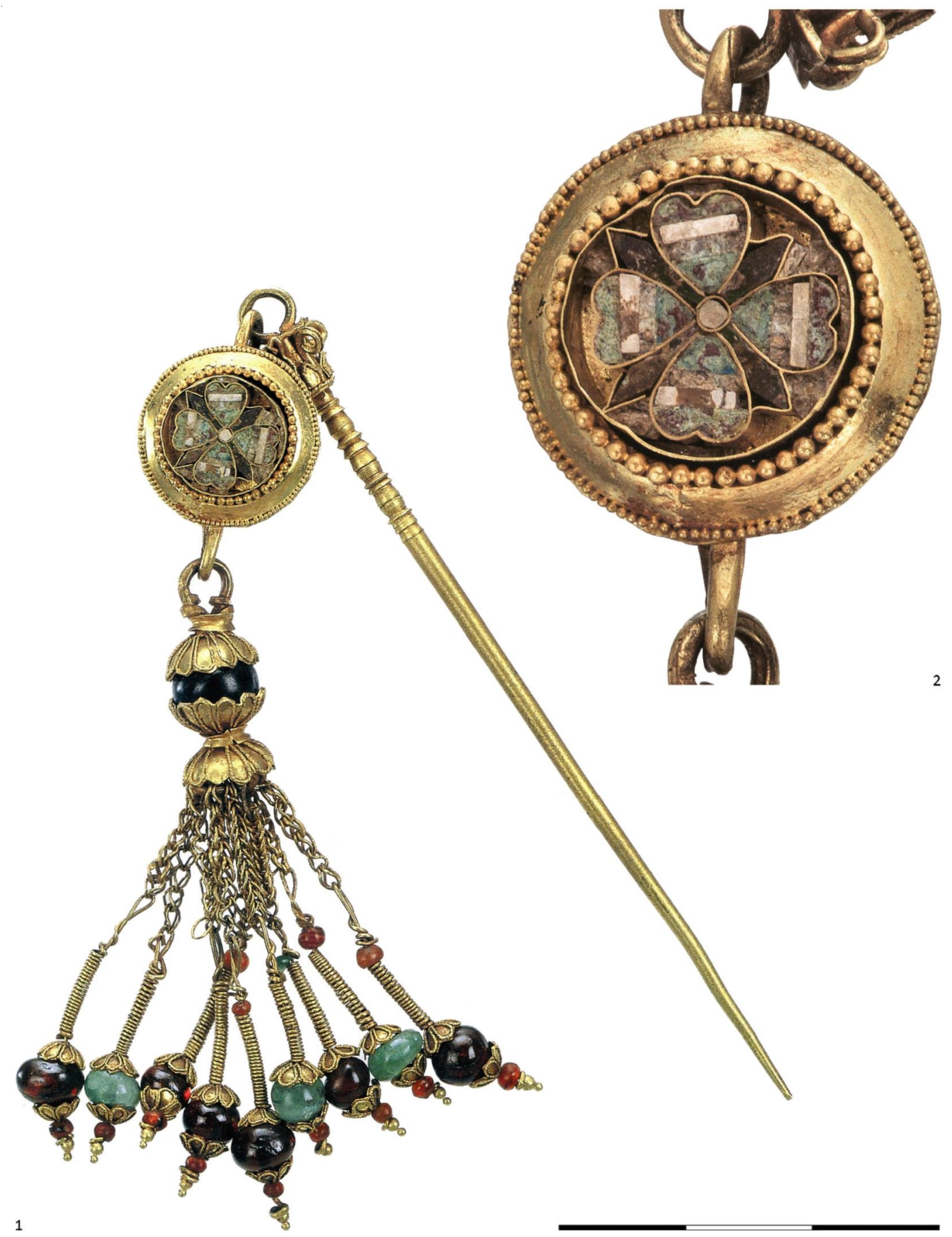

Рис. 4. Артюховский курган. Гробница І. Золотая булавка со щитком в технике клуазонне (Санкт-Петербург, Гос. Эрмитаж, инв. № Арт. 7):

1 - общий вид (по: [Kat. Bonn, 1997, S. 206]); 2 - деталь (по: [Калашник 2014, с. 255])

Fig. 4. Artyukhov Kurgan. Tomb I. Gold pin with a shield decorated in the cloisonné technique (Saint Petersburg, State Hermitage, inv. no. Арт. 7):

1 - general view (after: [Kat. Bonn, 1997, S. 206]); 2 - detail (after: [Kalashnik, 2014, p. 255]) 

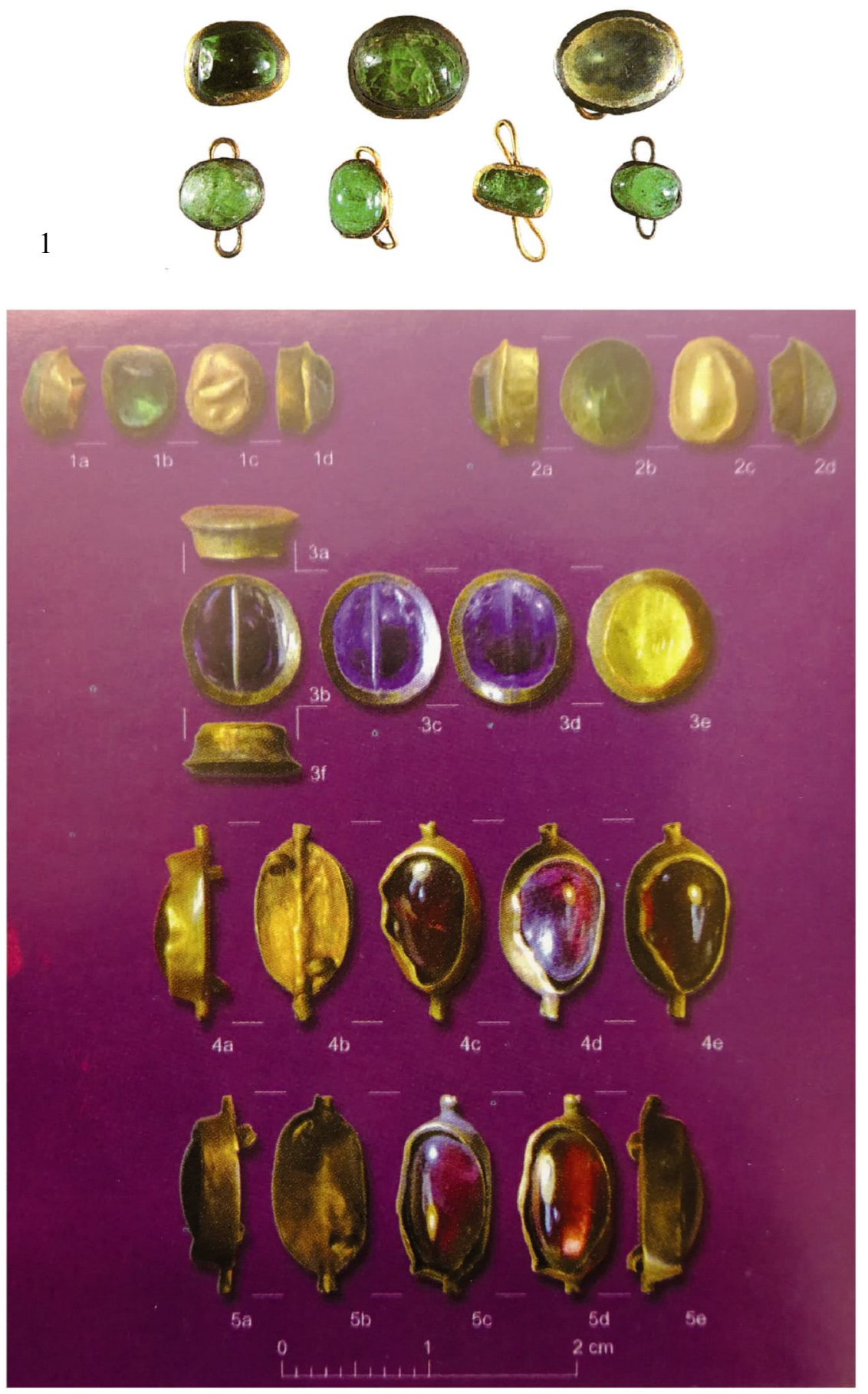

2

Рис. 5. Каралар. Курганы «А» и «С». Золотые касты со вставками (Анкара, Музей анатолийских цивилизаций, инв. № 182283):

1 - по: [Bingöl, 1999, s. 120, no. 124]; 2 - по: [Müller-Karpe, 2018, S. 332, Abb. 7]

Fig. 5. Karalar. Kurgans " $A$ " and "C". Gold settings with inlays (Ankara, Museum of Anatolian Civilzations, inv. no. 182283):

1 - after: [Bingöl, 1999, p. 120, no. 124]; 2 - after: [Müller-Karpe, 2018, S. 332, Abb. 7] 


\section{СПИСОК ЛИТЕРАТУРЫ}

Анфимов Н. В., 1987. Древнее золото Кубани. Краснодар : Краснодар. кн. изд-во. 232 с.

Анфимов Н. В., 2011. Древнее золото Кубани. 2-е изд. Краснодар : Традиция. 268 с.

Артамонов М. И., 1973. Сокровища саков. М. : Искусство. 280 с.

Белоусов А. В., Трейстер М. Ю., 2018. Парадный кинжал с надписью из княжеского сарматского погребения у с. Косика в Нижнем Поволжье // Аристей. Вып. XVIII. С. 92-128.

Василев В. П., 1988. Бронзови съдове от некропола при Требенище. Разкопки и проучвания. Т. ХІХ. София : Изд-во на Българската Академия на науките. 124 с.

Власова Е. В., 2010. Государственный Эрмитаж. Древности эллинские и местные // Античное наследие Кубани. Т. ІІІ. М. : Наука. С. 198-262.

Дворниченко В. В., Федоров-Давыдов Г. А., 1989. Памятники сарматской аристократии в Нижнем Поволжье // Сокровища сарматских вождей и древние города Поволжья. М. : Наука. С. 5-13.

Дворниченко В. В., Федоров-Давыдов Г. А., 1993. Сарматское погребение скептуха I в. н.э. у с. Косика Астраханской области // Вестник древней истории. № 3. С. 141-179.

Ждановский А. М., 1990. Новое погребение кочевников сарматского круга из Закубанья // Древние памятники Кубани. Краснодар : Упр. культуры Краснодар. крайисполкома. С. 102-116.

Зайцев Ю. П., Мордвинцева В. И., 2003. «Ногайчинский» курган в степном Крыму // Вестник древней истории. № 3. С. 61-99.

Засецкая И. П., 1979. Савроматские и сарматские погребения Никольского могильника в Нижнем Поволжье // Труды Гос. Эрмитажа. Вып. ХХ. С. 87-113.

Засецкая И. П., 2011. Сокровища кургана Хохлач. Новочеркасский клад. СПб. : Изд-во Гос. Эрмитажа. 328 с.

Калашник Ю. П., 2004. Два ожерелья из Херсонеса (об эллинистических традициях в римском ювелирном искусстве) // Эллинистические штудии в Эрмитаже : сб. ст. К шестидесятилетию Михаила Борисовича Пиотровского. СПб. : Изд-во Гос. Эрмитажа. С. 97-109.

Калашник Ю. П., 2014. Греческое золото в собрании Эрмитажа. Памятники античного ювелирного искусства из Северного Причерноморья. СПб. : Изд-во Гос. Эрмитажа. 278 с.

Клочков И. С., 1994. Две цилиндрические печати из сарматского погребения у с. Косика // Вестник древней истории. № 3. С. 210-217.

Лимберис Н. Ю., Марченко И. И., 2003. Стеклянные сосуды позднеэллинистического и римского времени из Прикубанья // Материалы и исследования по археологии Кубани. Вып. 3. С. 106-183.

Максимова М. И., 1979. Артюховский курган. Ленинград : Искусство. 152 с.

Матющенко В. И., Татаурова Л. В., 1997. Могильник Сидоровка в Омском Прииртышье. Новосибирск : Наука. 197 с.

Мордвинцева В.И., 2003. Полихромный звериный стиль. Симферополь : Универсум. 216 с.

Мордвинцева В. И., Трейстер М. Ю., 2007. Произведения торевтики и ювелирного искусства в Северном Причерноморье : в 3 т. Симферополь ; Бонн : Тарпан. Т. I - 308 с. ; т. II - 256 с. ; т. III - 206 с.

Мордвинцева В. И., Хачатурова Е. А., Юрченко Т. В., 2010. Сокровища древней Кубани. Древняя торевтика и ювелирное дело в Восточной Европе. Симферополь, Краснодар : Универсум. 448 с.

Отчет Императорской археологический комиссии за 1880 г. (Публ. 1882 г.). СПб. : Тип. Императ. акад. наук. 119 с.

Симоненко А. В., 1993. Сарматы Таврии. Киев : Наукова думка. 144 с.

Симоненко А. В., Лобай Б. И., 1991. Сарматы Северо-Западного Причерноморья в І в. н.э. Киев : Наукова думка. $108 \mathrm{c}$.

Трейстер М. Ю., 1994. Сарматская школа художественной торевтики (К открытию сервиза из Косики) // Вестник древней истории. № 3. С. 172-203.

Трейстер М. Ю., 2005. Сарматские воины Фарнака Боспорского (к вопросу об исторической интерпретации погребения в Косике) // Боспорский феномен. Проблема соотношения письменных и археологических источников. СПб. : Изд-во Гос. Эрмитажа. С. 322-330.

Трейстер М. Ю., 2007а. Торевтика и ювелирное дело в Северном Причерноморье. ІІ в. до н.э. - II в. н.э. (эллинистическая традиция) // Мордвинцева В.И., Трейстер М.Ю. Произведения торевтики и ювелир- 
ного искусства в Северном Причерноморье. II в. до н.э. - II в. н.э. Древняя торевтика и ювелирное дело в Восточной Европе. Т. І. Симферополь, Бонн : Тарпан. С. 15-194.

Трейстер М. Ю., 2007б. Типы накладных пластинчатых кастов, форма, материал и цвет вставок // Мордвинцева В. И., Трейстер М. Ю. Произведения торевтики и ювелирного искусства в Северном Причерноморье. ІІ в. до н.э. - II в. н.э. Древняя торевтика и ювелирное дело в Восточной Европе. Т. І. Симферополь, Бонн : Тарпан. С. 272-287.

Трейстер М. Ю., 2007в. Клуазонне // Мордвинцева В. И., Трейстер М. Ю. Произведения торевтики и ювелирного искусства в Северном Причерноморье. ІІ в. до н.э. - II в. н.э. Древняя торевтика и ювелирное дело в Восточной Европе. Т. І. Симферополь, Бонн : Тарпан. С. 288-294.

Трейстер М. Ю., 2012. Ахеменидские ювелирные украшения и украшения костюма из драгоценных металлов из Южного Приуралья. Изделия ахеменидского круга и местные подражания. Произведения постахеменидской традиции // Влияния ахеменидской культуры в Южном Приуралье (V-III вв. до н.э.). Древняя торевтика и ювелирное дело в Восточной Европе. Вып. 5, т. 1. М. : Таус. С. 134-167.

Трейстер М. Ю., 2015а. Золото Фанагории. Типологический, стилистический и хронологический анализ // Золото Фанагории. Материалы по археологии и истории Фанагории. Т. 2. М. : Ин-т археологии РАН. С. 77-181.

Трейстер М. Ю., 2015б. Каталог. Институт археологии РАН // Золото Фанагории. Материалы по археологии и истории Фанагории. Т. 2. М. : Ин-т археологии РАН. С. 391-534.

Трейстер М. Ю., 2018. Драгоценный поясной набор из элитного погребения кочевника у с. Косика // Нижневолжский археологический вестник. Т. 17, № 1. С. 108-143. DOI: http://doi.org/10.15688/nav.jvolsu.2018.1.6.

Трейстер М. Ю., 2019. Скарабеоид из погребения № 1 кургана № 1/2015 могильника Чеботарев-V (о ближневосточных печатях в погребениях среднесарматского времени) // Российская археология. № 1. С. 20-31. DOI: http://doi.org/10.31857/S086960630004111-1.

Трейстер М. Ю., 2020а. Ахеменидская цилиндрическая печать из Косики // «Боспорский стадий. Греки и их соседи в Северном Причерноморье античной эпохи (к 70-летию Ю.А. Виноградова)». Археологические вести. Вып. 29. СПб. : Ин-т истории материальной культуры РАН. С. 100-110.

Трейстер М. Ю., 2020б. Пектораль из Косики // Вестник древней истории. Т. 80, № 2. С. 377-409. DOI: http:// doi.org/10.31857/S032103910009661-0.

Штейн В. Ф., 1968. Пряжка с изображением ежей из Сибирской коллекции Эрмитажа // Советская археология. №2. C. 269-272.

Abdullaev K. A., 2008. Bactrian Gold Buckle with the Contest Between a Hero and a Centaur (Herakles and Nessos?) // Parthica. T. 10. P. 135-149.

Angelini M., 2011. Note sulla bronzistica greca arcaica attraverso lo studio delle tecniche di fabbricazione del cratere da Trebenište // Bollettino di archeologia on line. Vol. II, 2011/4. P. 92-124.

Arik R. O., 1934. Karalar Hafriyati // Türk Tarih, Arkeologya ve Etnografya Dergisi. T. 2. P. 102-167.

Arik R., Coupry J., 1935. Les tumuli de Karalar et la sépulture du roi Déiotaros II // Revue Archéologique. T. 6. P. $133-151$.

Atasoy S., 1974. The Kocakizlar Tumulus in Eskisehir, Turkey // American Journal of Archaeology. Vol. 78. P. 255-263.

Belousov A. V., Treister M., 2020. Inscribed Ceremonial Dagger from Princely Sarmatian Burial near the Village of Kosika in the Lower Volga Region // Ancient Civilizations from Scythia to Siberia. Vol. 26, no. 1. P. 172-206.

Bingöl F. R. I., 1999. Anadolu medenizetleri müzesi. Antik takilar. Ankara : T.C. Kültür ve Turizm Bakanlığı Anıtlar ve Müzeler Gnl. Müd. 233 s.

Brosseder U., 2011. Belt Plaques as an Indicator of East-West Relations in the Eurasian Steppe at the Turn of the Millennia // Xiongnu Archaeology. Multidisciplinary Perspectives of the First Steppe Empire in Inner Asia. Bonn Contributions to Asian Archaeology, Bd. 5. Bonn : Vor- und Frühgeschichtliche Archäologie, Rheinische Friedrich-Wilhelms-Universität Bonn. P. 349-424.

Caner E., 1983. Fibeln in Anatolien. I. Prähistorische Bronzefunde Abt. XIV, Bd. 8. München : C.H. Beck. 223 S.

Cat. Amsterdam, 2004. Kalashnik Yu. Greek Gold. From the Treasure Rooms of the Hermitage. Zwolle : Lund Humphries in association with the Hermitage. $127 \mathrm{p}$.

Cat. Dallas, 1990. Bromberg A. M. Gold of Greece. Jewelry and Ornaments from the Benaki Museum. Dallas : Dallas Museum of Art. $112 \mathrm{p}$.

Cat. Malibu, 2007. Greeks on the Black Sea. Ancient Art from the Hermitage. Los Angeles : Getty Publications. 307 p. 
Cat. New York, 2000. The Year One. Art of the Ancient World. East and West. New York : The Metropolitan Museum of Art. 192 p.

Cat. New York, 2016. Pergamon and the Hellenistic Kingdoms of the Ancient World. The Metropolitan Museum of Art. New Haven, London : The Metropolitan Museum of Art. 368 p.

Cat. Paris, 2001. L'or des Amazones. Paris : Editions Findakly / Paris musées. 300 p.

Cat. Rome, 2005. I Tesori della steppa di Astrakhan. Milano : Mondadori Electa. 183 p.

Coupry J., 1937. A propos des tumuli de Karalar // Revue archéologique. T. 9. P. 86-88.

Coşkun A., 2005. Amicitiae und politische Ambitionen im Kontext der causa Deiotariana (45 v. Chr.) // Roms Auswärtige Freunde in der späten Republik und im frühen Prinzipat. Göttingen : Ruprecht. S. 127-154.

Coşkun A., 2013a. Deiotaros of Galatia // The Encyclopedia of Ancient History. Malden, MA : Wiley-Blackwell. P. $1963-1964$.

Coşkun A., 2013b. War der Galaterkönig Deiotaros ein Städtegründer? Neue Vorschläge zu einigen kleinasiatischen Toponymen auf Sin-/Syn- // Gephyra. Vol. 10. S. 152-162.

Coşkun A., 2014. Latène-Artefakte im hellenistischen Kleinasien : ein problematisches Kriterium für die Bestimmung der ethnischen Identität(en) der Galater// Istanbuler Mitteilungen. Bd. 64. S. 129-162.

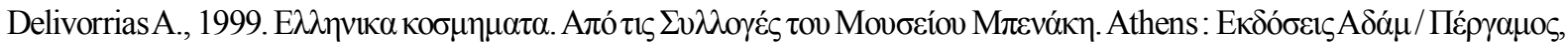

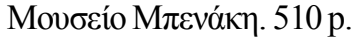

Deppert-Lippitz B., 1985. Griechischer Goldschmuck. Mainz : von Zabern. 322 S.

Despini Ai., 1996. Greek Art. Ancient Gold Jewellery. Athens : Ekdotiki Athinon. 292 p.

Dittenberger, W. (ed.), 1882. Inscriptiones Atticae aetatis romanae. Pars II. Tituli sepulcrales. Tituli memoriales. Fragmenta incerta. Addenda et corrigenda. Indices. Berlin : Reimer. 193 p.

Dvornitchenko V. V., Fedorov-Davydov G. A., 1994. Trésors des tombes de l'aristocratie sarmate au nord de la Caspienne // Les dossiers d'archéologie. No. 194. P. 66-75.

Faust S., 1994. Die Klinen // Das Wrack. Der antike Schiffsfund von Mahdia. Köln : Rheinland Verlag GmbH. S. 573-606.

French D. H., 2003. Roman, Late Roman and Byzantine Inscriptions of Ancyra. Ankara : Foundation of Museum of Anatolian Civilizations. 223 p.

Gagetti E., 2006. Preziose sculture di età ellenistica e romana. Il Filarete. Pubblicazioni della Facoltà di Lettere e Filosofia dell’Università degli Studi di Milano. Vol. 240. Milano : LED Edizioni Universitarie. 712 p.

Ghirshman R., 1962. Iran. Parther und Sasaniden. München : C.H. Beck. 404 S.

Hackens T., Lévy E., 1965. Trésor hellénistique trouvé à Délos en 1964 // Bulletin de correspondance hellénique. T. 89. P. 503-566.

Hadjidakis P. J., 2003. Delos. Athens : Eurobank, Latsis Group, Editions Olkos. 455 p.

Higgins R. A., 1980. Greek and Roman Jewellery. London : Methuen. 243 p.

Hofeneder A., 2004. Kann man Kamma, die Frau des Galatertetrarchen Sinatos, für die keltische Religion heranziehen? // Ad Fontes! Festschrift für Gerhard Dobesch zum fünfundsechzigsten Geburtstag am 15. September 2004. Wien : Im Eigenverlag der Herausgeber. S. 705-711.

Hoffmann H., von Claer V., 1968. Antiker Gold- und Silberschmuck : Museum für Kunst und Gewerbe Hamburg. Mainz : von Zabern. $246 \mathrm{~S}$.

Jackson M. M., 2010. New Jewellery Evidence from the Antikythera Shipwreck : A Stylistic and Chronological Analysis // Bulletin de correspondance hellénique. T. 134. P. 177-194.

Jackson M., 2017. Hellenistic Gold Jewellery in the Benaki Museum, Athens. Mouseio Benaki $10^{\text {th }}$ Suppl. Athens : Benaki Museum. $176 \mathrm{p}$.

Jacobsthal P., 1956. Greek Pins and their Connections with Europe and Asia. Oxford : Clarendon Press. 250 p.

Kat. Bonn, 1997. Zwei Gesichter der Eremitage. Die Skythen und ihr Gold. Bonn : Kunst-und Ausstellungshalle der Bundesrepublik Deutschland; Ostfildern : Hatje Cantz Verlag. 267 S.

Kat. Bonn, 2010. Gerettete Schätze Afghanistan. Die Sammlung des Nationalmuseums in Kabul. Bonn : Kunst- und Ausstellungshalle der BRD. $288 \mathrm{~S}$.

Kat. Frankfurt, 1994. Goldhelm. Schwert und Silberschätze. Reichtümer aus 6000 Jahren rumänischer Vergangenheit. Frankfurt : Museum für Vor- und Frühgeschichte, Archäologisches Museum. $257 \mathrm{~S}$. 
Klochkov I. S., 1996. Two Cylinder Seals from a Sarmatian Grave near Kosika // Ancient Civilizations from Scythia to Siberia. Vol. 3. P. 38-48.

Koryakova L., 2006. On the Northern Periphery of the Nomadic World : Research in the Trans-Ural Region // The Golden Deer of Eurasia. Perspectives on the Steppe Nomads of the Ancient World. New York : The Metropolitan Museum of Art. P. 102-113.

Kourkoumelis D., 2012. Transport Amphorae// The Antikythera Shipwreck, the Ship, the Treasures, the Mechanism. Exhibition catalogue. Athens : Hellenic Ministry of Culture and Tourism - National Archaeological Museum. P. 208-215.

Krug A., 1987. Nero’s Augenglas. Realia zu einer Anekdote // Archéologie et Médecine, VIIèmes Rencontres Internationales d'Archéologie et d'Histoire, Antibes 1986. Antibes : Musée archéologique. P. 459-475.

Lungu V., CovacefZ., Chera K., 2012. Bijuterii antice din aur din olecţiile Muzeului de Istorie Naţională şi. Arheologie Constanța. Biblotheca Tomitana. Vol. VI. Constanța : Ex Ponto. 147 p.

Marčenko I.I., Limberis N.J., 2008. Römische Importe in sarmatischen und maiotischen Denkmälern des Kubangebietes // Simonenko A., Marčenko I.I., Limberis N.J. Römische Importe in sarmatischen und maiotischen Gräbern. Archäologie in Eurasien. Bd. 25. Mainz : von Zabern. S. 267-400.

Margulies E., 1967. Cloisonné enamel // Survey of Persian Art. Vol. II. Tehran : Persian Art ; London : Oxford University Press ; Tokyo : Teiji Shobo. P. 779-783.

Mitchell S., 1982. Regional Epigraphic Catalogues of Asia Minor. Vol. 2: The Ankara District: The Inscriptions of North Galatia. Oxford : British Archaeological Reports. 461 p.

Mordvintseva V. I., Zaitsev Y. P., 2003. The Nogaichik Burial-Mound in the Steppes of the Crimea // Ancient Civilizations from Scythia to Siberia. Vol. 9. P. 193-257.

Müller-Karpe A., 2018. Die Juwelen der Königin Berenike. Antiker Schmuck zwischen Raubgrabungen und Wissenschaft // Festschrift für Heide Froning. Studies in Honour of Heide Froning. Istanbul : E Yayinlari. S. 313-334.

Nenna M.-D., 1999. Les Verres. Exploration archéologique de Délos, 37. Paris, Athènes : École Française d'Athènes. 216 p.

Parachaud K., 2015. Présences “celtiques” en Méditerranée orientale au regard des cultures matérielles de La Tène (Ve-Ier siècle av. n. è.). Vols. 1-2. Université Toulouse - Jean Jaurès. 174 p.

Parker V., 2018. Deiotarus: zur Karriere eines römischen Klientelkönigs // Electrum. Vol. 25. S. 187-208. DOI: http:// doi.org/10.4467/20800909EL.18.009.8929.

Pfeiler B., 1970. Römischer Goldschmuck des ersten und zweiten Jahrhunderts n. Chr. nach datierten Funden. Mainz : von Zabern. $136 \mathrm{~S}$.

Pfeiler-Lippitz B., 1972. Späthellenistische Goldschmiedearbeiten // Antike Kunst. Jg. 15, Heft 2. S. 107-119.

Pfrommer M., 1990. Untersuchungen zur Chronologie früh- und hochhellenistischen Goldschmucks (Istanbuler Forschungen 37). Tübingen : E. Wasmuth. $470 \mathrm{~S}$.

Plantzos D., 1999. Hellenistic Engraved Gems. Oxford : Clarendon Press. 148 p.

Platz-Horster G., 2010. Kleine Praser and Chromium-bearing Chalcedonies. About a Small Group of Engraved Gems // Pallas. Vol. 83. P. 179-202.

Pougatchenkova G., 1978. Les trésors de Dalverzine-Tépé. Leningrad : Eìd. d'art Aurore. 102 p.

Regional epigraphic catalogues of Asia Minor II: the Ankara district, the inscriptions of North Galatia. URL: https://epigraphy.packhum.org/text/267821 (accessed 30.11.2020).

Rice K. E., 2016. A tomb with a view: Constructing place and identity in the funerary monuments of Hellenistic Anatolia. Dissertation. University of North Carolina at Chapel Hill. Chapel Hill. 578 p.

Rolley C., 2003. Le cratère // La tombe princière de Vix. Paris : Picard et Société des amis du musée du Châtillonais. P. 76-143.

Rosenberg M., 1921. Geschichte der Goldschmiedekunst auf technischer Grundlage. Zellenschmelz. Bd. 1-2. Frankfurt : Joseph Baer \& Co. $80 \mathrm{~S}$.

Rudenko S. I., 1962. Die Sibirische Sammlung Peters I. Sammlung archäologischen Quellen D3-9. Moskau, Leningrad : Verlag der Akademie der Wissenschaften der UdSSR. 67 S.

Ruxer M. S., Kubczak J., 1972. Naszyjnik grecki w okresie hellenistycznym i rzymskim. Warsaw, Poznań : Państwowe Wydawn. Naukowe, Oddział w Poznaniu. 272 p. 
Sarianidi V. I., 1985. Baktrisches Gold. Leningrad : Aurova-Kunstverlag. 264 S.

Ščepinskij A. A., 1994. Über die Aristokratie der Sarmaten im nördlichen Schwarzmeergebiet // Zeitschrift für Archäologie. Bd. 28. S. 87-106.

Segall B., 1938. Katalog der Goldschmiede-Arbeiten. Museum Benaki. Athen : Museum Benaki. 220 S.

Shaw I., Bunbury J., Jameson R., 1999. Emerald Mining in Roman and Byzantine Egypt // Journal of Roman Archaeology. Vol. 12. P. 203-215.

Spickermann W., 2006. "Deiotaros" // Der Neue Pauly, Herausgegeben von: Hubert Cancik, Helmuth Schneider (Antike), Manfred Landfester (Rezeptions- und Wissenschaftsgeschichte). URL : http://dx.doi.org/10.1163/ 1574-9347_dnp_e313010(accessed 22.09.2020).

Stassinopoulou E., 2012. The Golden Jewels and the Silver Vases // The Antikythera Shipwreck, the Ship, the Treasures, the Mechanism. Exhibition catalogue. Athens : Hellenic Ministry of Culture and Tourism - National Archaeological Museum. P. 146-151.

Strobel K., 2002. Die Staatenbildung bei den kleinasiatischen Galatern. Politisch-historische und kulturelle Prozesse im hellenistischen Zentralanatolien // Brückenland Anatolien? Ursachen, Extensität und Modi des Kulturaustausches zwischen Anatolien und seinen Nachbarn. Tübingen : Attempto. S. 231-293.

Syme R. 1995. Deiotarus // Syme R. Anatolica. Studies in Strabo. Oxford : Clarendon Press. P. 127-136.

Tarditi C., 2016. Bronze Vessels from the Acropolis. Style and Decoration in Athenian Production Between the Sixth and the Fifth Centuries BC. Thiasos Monografie. Vol. 7. Roma : Edizioni Quasar. 410 p.

Treister M. Y., 1997. New Discoveries of Sarmatian Complexes of the $11^{\text {st }}$ Century AD. A Survey of Publications in VDI // Ancient Civilizations from Scythia to Siberia. Vol. 4. P. 35-100.

Treister M., 2002. Two Golden Bracelets from Olbia in the Walters Art Gallery// Ancient Civilizations from Scythia to Siberia. Vol. 8. P. 17-68.

Treister M. Y., 2004a. Cloisonné-and Champlevé-decoration in the Gold Work of the Late Hellenistic-Early Imperial Periods // Acta Archaeologica. Vol. 75, no. 2. P. 189-219.

Treister M. Y., 2004b. Polychrome Necklaces from the Late Hellenistic Period (On the Question of the Origin of Necklaces with Butterfly-shaped Pendants) // Ancient Civilizations from Scythia to Siberia. Vol. 10. P. 199-257.

Treister M., 2005. On a Vessel with Figured Friezes from a Private Collection, on Burials in Kosika and Once More on the "Ampsalakos School" // Ancient Civilizations from Scythia to Siberia. Vol. 11, Nos. 3-4. P. $199-255$.

Treister M., 2006. Late Hellenistic Polychrome Necklaces // Common Ground : Archaeology, Art, Science, and Humanities, Proceedings of the XVI International Congress of Classical Archaeology. Oxbow Monograph XX. Oxford : Oxbow Books. P. 518-522.

Tselekas P., 2012. The Coins // The Antikythera Shipwreck, the Ship, the Treasures, the Mechanism. Exhibition catalogue. Athens : Hellenic Ministry of Culture and Tourism - National Archaeological Museum. P. $216-226$.

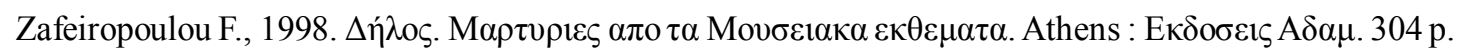

Zinc S., 2019. Polychromy, architectural, Greek and Roman // Oxford Classical Dictionary. DOI: https://doi.org/ 10.1093/acrefore/9780199381135.013.8184.

Zwierlein-Diehl E., 2007. Antike Gemmen und Ihr Nachleben. Berlin : Walter de Gruyter. 567 S.

\section{REFERENCES}

Anfimov N.V., 1987. Drevnee zoloto Kubani [Ancient Gold of Kuban]. Krasnodar, Krasnodarskoe knizhnoe izdatel'stvo Publ. 232 p.

Anfimov N.V., 2011. Drevnee zoloto Kubani [Ancient Gold of Kuban]. 2 ${ }^{\text {nd }}$ ed. Krasnodar, Traditsiya Publ. 268 p. Artamonov M.I., 1973. The Treasures of Saka. Moscow, Iskusstvo Publ. 280 p.

Belousov A.V., Treister M.Yu., 2018. Paradnyy kinzhal s nadpis’yu iz knyazheskogo sarmatskogo pogrebeniya u s. Kosika v Nizhnem Povolzh'e [The Ceremonial Dagger with the Inscription from the Princely Sarmatian Burial near the Village Kosika in the Lower Volga Region]. Aristey [Aristaios], iss. XVIII, pp. 92-128.

Vasilev V.P., 1988. Bronzovi sadove ot nekropola pri Trebenishche [Bronze Vessels from the Necropolis of Trebenishte]. Ausgrabungen und Forschungen, XIX. Sofia, Bulgarian Academy of Sciences. 124 p. 
Vlasova E.V., 2010. Gosudarstvennyy Ermitazh. Drevnosti ellinskie i mestnye [The State Hermitage. Hellenic and Local Antiquities]. Antichnoe nasledie Kubani [The Ancient Heritage of Kuban]. Vol. III. Moscow, Nauka Publ., pp. 198-262.

Dvornichenko V.V., Fedorov-Davydov G.A., 1989. Pamyatniki sarmatskoy aristokratii v Nizhnem Povolzh'e [The Monuments of Sarmatian Aristocracy in the Lower Volga Region]. Sokrovishcha sarmatskikh vozhdey $i$ drevnie goroda Povolzh'ya [The Treasures of Sarmatian Chieftains and the Ancient Cities of the Volga Region]. Moscow, Nauka Publ., pp. 5-13.

Dvornichenko V.V., Fedorov-Davydov G.A., 1993. Sarmatskoe pogrebenie skeptukha I v. n.e. u s. Kosika Astrakhanskoy oblasti [Sarmatian Burial of Skeptuch of the $1^{\text {st }}$ Century Near the Village of Kosika of the Astrakhan Region]. Vestnik drevnei istorii [Journal of Ancient History], no. 3, pp. 141-179.

Zhdanovskiy A.M., 1990. Novoe pogrebenie kochevnikov sarmatskogo kruga iz Zakuban'ya [A New Burial of the Nomads of Sarmatian Circle in the Transkuban Region]. Drevnie pamyatniki Kubani [Ancient Monuments of Kuban]. Krasnodar, Department of Culture of the Krasnodar Regional Executive Committee, pp. 102-116.

Zaytsev Yu.P., Mordvintseva V.I., 2003. «Nogaychinskiy» kurgan v stepmom Krymu [The "Nogaichinsky” Barrow in the Steppe-Land Crimea]. Vestnik drevnei istorii [Journal of Ancient History], no. 3, pp. 61-99.

Zasetskaya I.P., 1979. Savromatskie i sarmatskie pogrebeniya Nikol'skogo mogil'nika v Nizhnem Povolzh'e [Sauromatian and Sarmatian Burials of the Nikol'skoe Cemetery in the Lower Volga Region]. Trudy Gosudarstvennogo Ermitazha [Proceedings of the State Hermitage], iss. XX, pp. 87-113.

Zasetskaya I.P., 2011. Sokrovishcha kurgana Khokhlach. Novocherkasskiy klad [The Treasures of Khokhlach Burial-mound. The Novocherkassk Hoard]. Saint Petersburg, The State Hermitage. 328 p.

Kalashnik Yu.P., 2004. Dva ozherel'ya iz Khersonesa (ob ellinisticheskikh traditsiyakh v rimskom yuvelirnom iskusstve) [Two Necklaces from Chersonessos (about the Hellenistic Traditions in Roman Jewelry Art)]. Ellinisticheskie shtudii v Ermitazhe: sbornik statey. K shestidesyatiletiyu Mikhaila Borisovicha Piotrovskogo [Hellenistic Studies in the Hermitage. Collection of articles. On the sixtieth Birthday of Mikhail Borisovich Piotrovskiy]. Saint Petersburg, The State Hermitage, pp. 97-109.

Kalashnik Yu.P., 2014. Grecheskoe zoloto v sobranii Ermitazha. Pamyatniki antichnogo yuvelirnogo iskusstva iz Severnogo Prichernomor'ya [Greek Gold in the Collection of the Hermitage. Monuments of Antique Jewelry Art from the North Pontic Region]. Saint Petersburg, The State Hermitage. 278 p.

Klochkov I.S., 1994. Dve tsilindricheskie pechati iz sarmatskogo pogrebeniya u s. Kosika [Two Cylinder Seals From the Sarmatian Grave near Kosika (the Lower Volga)]. Vestnik drevnei istorii [Journal of Ancient History], no. 3, pp. 210-217.

Limberis N.Yu., Marchenko I.I., 2003. Steklyannye sosudy pozdneellinisticheskogo i rimskogo vremeni iz Prikuban'ya [Glass Vessels of the Late Hellenistic and Roman Periods from the Kuban Region]. Materialy i issledovaniya po arkheologii Kubani [Materials and Investigations on the Archaeology of Kuban], iss. 3, pp. 106-183.

Maksimova M.I., 1979. Artyukhovskiy kurgan [Artyukhov Burial-mound]. Leningrad, Iskusstvo Publ. 152 p.

Matyushchenko V.I., Tataurova L.V., 1997. Mogil'nik Sidorovka v Omskom Priirtysh 'e [Burial-ground Sidorovka in the Irtysh Basin of Omsk Region]. Novosibirsk, Nauka Publ. 197 p.

Mordvintseva V.I., 2003. Polihromnyy zverinyy stil' [The Polychrome Animal Style]. Simferopol, Universum Publ. 216 p.

Mordvintseva V.I., Treister M.Yu., 2007. Proizvedeniya torevtiki i yuvelirnogo iskusstva v Severnom Prichernomor' $e$ : $v 3 t$. [Items of Toreutics and Jewelry Art in the Northern Black Sea Region $\left(2^{\text {nd }} c\right.$. BC $-2^{\text {nd }}$ c. AD). In 3 vols.]. Simferopol, Bonn, Tarpan Publ. Vol. I. 308 p.; vol. II. 256 p.; vol. III. 206 p.

Mordvintseva V.I., Khachaturova E.A., Yurchenko T.V., 2010. Sokrovishcha drevney Kubani [The Treasures of Ancient Kuban]. Drevnyaya torevtika i yuvelirnoe delo v Vostochnoy Evrope [Ancient Toreutics and Jewelry in Eastern Europe]. Simferopol, Krasnodar, Universum Publ. 448 p.

Otchet Imperatorskoy arheologicheskoy komissii za 1880 god [Report of the Imperial Archaeological Commission for 1880]. (Published in 1882). Saint Petersburg, Printing House of the Imperial Academy of Sciences. 119 p.

Simonenko A.V., 1993. Sarmaty Tavrii [The Sarmatians of Tauride]. Kiev, Naukova dumka Publ. 144 p.

Simonenko A.V., Lobay B.I., 1991. Sarmaty Severo-Zapadnogo Prichernomor'ya v Iv. n.e. [The Sarmatians of the North-Western Pontic Area in the $1^{\text {st }}$ Century AD]. Kiev, Naukova dumka Publ. 108 p.

Treister M.Yu., 1994. Sarmatskaya shkola khudozhestvennoy torevtiki (K otkrytiyu serviza iz Kosiki) [Sarmatian Toreutic School (A Tableware Set from Koika)]. Vestnik drevnei istorii [Journal of Ancient History], no. 3, pp. 172-203. 
Treister M.Yu., 2005. Sarmatskie voiny Farnaka Bosporskogo (k voprosu ob istoricheskoy interpretatsii pogrebeniya $\mathrm{v}$ Kosike) [Sarmatian Warriors of Pharnaces of Bosporus (to the Question of Historical Interpretation of the Burial in Kosika)]. Bosporskiy fenomen. Problema sootnosheniya pis'mennykh $i$ arkheologicheskikh istochnikov [The Bosporan Phenomenon. The Problem of the Corrtelation of the Written and Archaeological Sources]. Saint Petersburg, The State Hermitage, pp. 322-330.

Treister M.Yu., 2007a. Torevtika i yuvelirnoe delo v Severnom Prichernomor'e. II v. do n.e. - II v. n.e. (ellinisticheskaya traditsiya) [Toreutics and Jewelry in the North Pontic Area. $2^{\text {nd }}$ Century BC $-2^{\text {nd }}$ Century AD (Hellenistic Tradition]. Mordvintseva V.I., Treister M.Yu. Proizvedeniya torevtiki i yuvelirnogo iskusstva v Severnom Prichernomor'e. Drevnyaya torevtika i yuvelirnoe delo v Vostochnoy Evrope [Items of Toreutics and Jewelry Art in the Northern Black Sea Region $\left(2^{\text {nd }} c . B C-2^{\text {nd }} c . A D\right)$ Ancient Toreutics and Jewelry in Eastern Europe]. Vol. 1. Simferopol, Bonn, Tarpan Publ., pp. 15-194.

Treister M.Yu., 2007b. Tipy nakladnykh plastinchatykh kastov, forma, material i tsvet vstavok [The Types of applied Lamellar Settings, the Shape, Material and Colour of the Inlays]. Mordvintseva V.I., Treister M. Yu. Proizvedeniya torevtiki i yuvelirnogo iskusstva $v$ Severnom Prichernomor'e. Drevnyaya torevtika i yuvelirnoe delo $v$ Vostochnoy Evrope [Items of Toreutics and Jewelry Art in the Northern Black Sea Region $\left(2^{\text {nd }} c .8 C-2^{\text {nd }} c . A D\right)$ Ancient Toreutics and Jewelry in Eastern Europe]. Vol. 1. Simferopol, Bonn, Tarpan Publ., pp. 272-287.

Treister M.Yu., 2007c. Cloisonné. Mordvintseva V.I., Treister M.Yu. Proizvedeniya torevtiki i yuvelirnogo iskusstva $v$ Severnom Prichernomor'e. Drevnyaya torevtika i yuvelirnoe delo v Vostochnoy Evrope [Items of Toreutics and Jewelry Art in the Northern Black Sea Region $\left(2^{\text {nd }} c . B C-2^{\text {nd }} c . A D\right)$. Ancient Toreutics and Jewelry in Eastern Europe]. Vol. 1. Simferopol, Bonn, Tarpan Publ., pp. 288-294.

Treister M.Yu., 2012. Akhemenidskie yuvelirnye ukrasheniya i ukrasheniya kostyuma iz dragotsennykh metallov iz Yuzhnogo Priural'ya. Izdeliya akhemenidskogo kruga i mestnye podrazhaniya. Proizvedeniya postakhemenidskoy traditsii [Achaemenid Jewelry and Ornaments of Costume made of Precious Metals from the Southern Urals. Articles of the Achaemenid Circle and Local Imitations. Creations of the Post-Achaemenid Tradition]. Vliyaniya akhemenidskoy kul'tury $v$ Yuzhnom Priural'e (V-III vv. do n.e.). Drevnyaya torevtika i yuvelirnoe delo $v$ Vostochnoy Evrope [Influences of the Achaemenid Culture in Southern Urals $\left(5^{\text {th }}-3^{\text {rd }}\right.$ Centuries BC. Ancient Toreutics and Jewelry in Eastern Europe]. Iss. 5, vol. 1. Moscow, Taus Publ., pp. 134-167.

Treister M.Yu., 2015a. Zoloto Fanagorii. Tipologicheskiy, stilisticheskiy i khronologicheskiy analiz [The Gold of Phanagoria. Typological, Stylistic and Chronological Analysis]. Zoloto Fanagorii. Materialy po arkheologii $i$ istorii Fanagorii [The Gold of Phanagoria. Materials on the Archaeology and History of Phanagoria]. Vol. 2. Moscow, IA RAS, pp. 77-181.

Treister M.Yu., 2015b. Katalog. Institut arkheologii RAN [Catalogue. Institute of Archaeology, Russian Academy of Sciences]. Zoloto Fanagorii. Materialy po arkheologii i istorii Fanagorii [The Gold of Phanagoria. Materials on the Archaeology and History of Phanagoria]. Vol. 2. Moscow, Institute of Archaeology, Russian Academy of Sciences, pp. 391-534.

Treister M.Yu., 2018. Dragotsennyy poyasnoy nabor iz elitnogo pogrebeniya kochevnika u s. Kosika [A Precious Belt Set from the Nomadic Elite Burial near the Village of Kosika]. Nizhnevolzhskiy Arkheologicheskiy Vestnik [The Lower Volga Archaeological Bulletin], vol. 17, no. 1, pp. 108-143. DOI: http://doi.org/10.15688/ nav.jvolsu.2018.1.6

Treister M.Yu., 2019. Skarabeoid iz pogrebeniya № 1 kurgana № 1/2015 mogil'nika Chebotarev-V (o blizhnevostochnykh pechatyakh v pogrebeniyakh srednesarmatskogo vremeni) [A Scaraboid from Burial 1 of Burial-mound 1/2015 of the Chebotarev V Cemetery in the Lower Don Area (About the Near Eastern Seals in the Nomadic Burials of the Middle Sarmatian Period)]. Rossiiskaya arkheologiya [Russian Archaeology], no. 1, pp. 20-31. DOI: http://doi.org/10.31857/S086960630004111-1.

Treister M.Yu., 2020a. Akhemenidskaya tsilindricheskaya pechat' iz Kosiki [An Achaemenid Cylindrical Seal from Kosika]. "Bosporskiy stadiy. Greki i ikh sosedi v Severnom Prichernomor'e antichnoy epokhi (k 70-letiyu Yu.A. Vinogradova)». Arkheologicheskie vesti [The Bosporan Stadium. The Greeks and their Neighbors in the North Pontic Area in the Antiquity era (to the $70^{\text {th }}$ Anniversary of Yu.A. Vinogradov). Archaeological News]. Iss. 29. Saint Petersburg, IHMC RAS, pp. 100-110.

Treister M.Yu., 2020b. Pektoral' iz Kosiki [A Pectoral from Kosika]. Vestnik drevnei istorii [Journal of Ancient History], vol. 80, no. 2, pp. 377-409. DOI: http://doi.org/10.31857/S032103910009661-0.

Shtein V.F., 1968. Pryazhka s izobrazheniem ezhey iz Sibirskoy kollektsii Ermitazha [The Buckle with the Images of Hedgehogs from the Siberian Collection of the Hermitage]. Sovetskaja arkheologiya [Soviet Archaeology], no. 2, pp. 269-272. 
Abdullaev K.A., 2008. Bactrian Gold Buckle with the Contest Between a Hero and a Centaur (Herakles and Nessos?). Parthica, vol. 10, pp. 135-149.

Angelini M., 2011. Note sulla bronzistica greca arcaica attraverso lo studio delle tecniche di fabbricazione del cratere da Trebenište. Bollettino di archeologia on line. Vol. II, 2011/4, pp. 92-124.

Arik R.O., 1934. Karalar Hafriyati. Türk Tarih, Arkeologya ve Etnografya Dergisi, t. 2, pp. 102-167.

Arik R., Coupry J., 1935. Les tumuli de Karalar et la sépulture du roi Déiotaros II. Revue Archéologique, t. 6, pp. 133-151. Atasoy S., 1974. The Kocakizlar Tumulus in Eskisehir, Turkey. American Journal of Archaeology, vol. 78, p. 255-263.

Belousov A.V., Treister M., 2020. Inscribed Ceremonial Dagger from Princely Sarmatian Burial near the Village of Kosika in the Lower Volga Region. Ancient Civilizations from Scythia to Siberia, vol. 26, no. 1, pp. 172-206.

Bingöl F.R.I., 1999. Anadolu medenizetleri müzesi. Antik takilar. Ankara, T.C. Kültür ve Turizm Bakanlığı Anıtlar ve Müzeler Gnl. Müd. 233 s.

Brosseder U., 2011. Belt Plaques as an Indicator of East-West Relations in the Eurasian Steppe at the Turn of the Millennia. Xiongnu Archaeology. Multidisciplinary Perspectives of the First Steppe Empire in Inner Asia. Bonn Contributions to Asian Archaeology, 5. Bonn, Vor- und Frühgeschichtliche Archäologie, Rheinische Friedrich-Wilhelms-Universität Bonn, pp. 349-424.

Caner E., 1983. Fibeln in Anatolien. I. Prähistorische Bronzefunde Abt. XIV, Bd. 8. München, C.H. Beck. 223 S.

Cat. Amsterdam 2004. Kalashnik Yu. Greek Gold. From the Treasure Rooms of the Hermitage. Zwolle, Lund Humphries in association with the Hermitage. $127 \mathrm{p}$.

Cat. Dallas, 1990. Bromberg A.M. Gold of Greece. Jewelry and Ornaments from the Benaki Museum. Dallas, Dallas Museum of Art. $112 \mathrm{p}$.

Cat. Malibu, 2007. Greeks on the Black Sea. Ancient Art from the Hermitage. Los Angeles, Getty Publications. $307 \mathrm{p}$.

Cat. New York, 2000. The Year One. Art of the Ancient World. East and West. New York, The Metropolitan Museum of Art. $192 \mathrm{p}$.

Cat. New York, 2016. Pergamon and the Hellenistic Kingdoms of the Ancient World. The Metropolitan Museum of Art. New Haven, London, The Metropolitan Museum of Art. 368 p.

Cat. Paris, 2001. L'or des Amazones. Paris, Editions Findakly/ Paris musées. 300 p.

Cat. Rome, 2005. I Tesori della steppa di Astrakhan. Milano, Mondadori Electa. 183 p.

Coupry J., 1937. A propos des tumuli de Karalar. Revue archéologique, t. 9, pp. 86-88.

Coşkun A., 2005. Amicitiae und politische Ambitionen im Kontext der causa Deiotariana (45 v. Chr.). Roms Auswärtige Freunde in der späten Republik und im frühen Prinzipat. Göttingen, Ruprecht, S. 127-154.

Coşkun A., 2013a. Deiotaros of Galatia. The Encyclopedia of Ancient History. Malden, MA, Wiley-Blackwell, pp. 1963-1964.

Coşkun A., 2013b. War der Galaterkönig Deiotaros ein Städtegründer? Neue Vorschläge zu einigen kleinasiatischen Toponymen auf Sin-/Syn-. Gephyra, vol. 10, S. 152-162.

Coşkun A., 2014. Latène-Artefakte im hellenistischen Kleinasien: ein problematisches Kriterium für die Bestimmung der ethnischen Identität(en) der Galater. Istanbuler Mitteilungen, Bd. 64, S. 129-162.

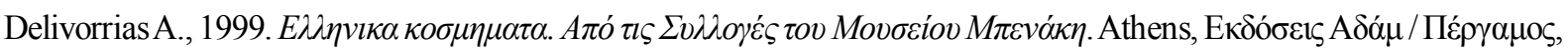

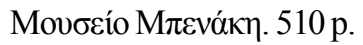

Deppert-Lippitz, B. 1985. Griechischer Goldschmuck. Mainz, von Zabern. 322 S.

Despini Ai., 1996. Greek Art. Ancient Gold Jewellery. Athens, Ekdotiki Athinon. 292 p.

Dittenberger, W. (ed.), 1882. Inscriptiones Atticae aetatis romanae. Pars II. Tituli sepulcrales. Tituli memoriales. Fragmenta incerta. Addenda et corrigenda. Indices. Berlin, Reimer. 193 p.

Dvornitchenko V.V., Fedorov-Davydov G.A., 1994. Trésors des tombes de l'aristocratie sarmate au nord de la Caspienne. Les dossiers d'archéologie, no. 194, pp. 66-75.

Faust S., 1994. Die Klinen. Das Wrack. Der antike Schiffsfund von Mahdia. Köln, Rheinland Verlag GmbH, S. 573-606.

French D.H., 2003. Roman, Late Roman and Byzantine Inscriptions of Ancyra. Ankara, Foundation of Museum of Anatolian Civilizations. 223 p. 
Gagetti E., 2006. Preziose sculture di età ellenistica e romana. Il Filarete. Pubblicazioni della Facoltà di Lettere e Filosofia dell’Università degli Studi di Milano. Vol. 240. Milano, LED Edizioni Universitarie. 712 p.

Ghirshman R., 1962. Iran. Parther und Sasaniden. München, C.H. Beck. 404 S.

Hackens T., Lévy E., 1965. Trésor hellénistique trouvé à Délos en 1964. Bulletin de correspondance hellénique, t. 89 , pp. 503-566.

Hadjidakis P.J., 2003. Delos. Athens, Eurobank, Latsis Group, Editions Olkos. 455 p.

Higgins R.A., 1980. Greek and Roman Jewellery. London, Methuen. 243 p.

Hofeneder A., 2004. Kann man Kamma, die Frau des Galatertetrarchen Sinatos, für die keltische Religion heranziehen? Ad Fontes! Festschrift für Gerhard Dobesch zum fünfundsechzigsten Geburtstag am 15. September 2004. Wien, Im Eigenverlag der Herausgeber, S. 705-711.

Hoffmann H., von Claer V., 1968. Antiker Gold- und Silberschmuck: Museum für Kunst und Gewerbe Hamburg. Mainz, von Zabern. 246 S.

Jackson M.M., 2010. New Jewellery Evidence from the Antikythera Shipwreck: A Stylistic and Chronological Analysis. Bulletin de correspondance hellénique, t. 134, pp. 177-194.

Jackson M., 2017. Hellenistic Gold Jewellery in the Benaki Museum, Athens. Mouseio Benaki 10 ${ }^{\text {th }}$ Suppl. Athens, Benaki Museum. $176 \mathrm{p}$.

Jacobsthal P., 1956. Greek Pins and their Connections with Europe and Asia. Oxford, Clarendon Press. 250 p.

Kat. Bonn, 1997. Zwei Gesichter der Eremitage. Die Skythen und ihr Gold. Bonn, Kunst-und Ausstellungshalle der Bundesrepublik Deutschland; Ostfildern, Hatje Cantz Verlag. 267 S.

Kat. Bonn, 2010. Gerettete Schätze Afghanistan. Die Sammlung des Nationalmuseums in Kabul. Bonn, Kunstund Ausstellungshalle der BRD. $288 \mathrm{~S}$.

Kat. Frankfurt, 1994. Goldhelm. Schwert und Silberschätze. Reichtümer aus 6000 Jahren rumänischer Vergangenheit. Frankfurt, Museum für Vor- und Frühgeschichte, Archäologisches Museum. $257 \mathrm{~S}$.

Klochkov I.S., 1996. Two Cylinder Seals from a Sarmatian Grave near Kosika. Ancient Civilizations from Scythia to Siberia, vol. 3, pp. 38-48.

Koryakova L., 2006. On the Northern Periphery of the Nomadic World: Research in the Trans-Ural Region. The Golden Deer of Eurasia. Perspectives on the Steppe Nomads of the Ancient World. New York, The Metropolitan Museum of Art, pp. 102-113.

Kourkoumelis D., 2012. Transport Amphorae. The Antikythera Shipwreck, the Ship, the Treasures, the Mechanism. Exhibition catalogue. Athens, Hellenic Ministry of Culture and Tourism - National Archaeological Museum, pp. 208-215.

Krug A., 1987. Nero's Augenglas. Realia zu einer Anekdote. Archéologie et Médecine, VIIèmes Rencontres Internationales d'Archéologie et d'Histoire, Antibes 1986. Antibes, Musée archéologique, pp. 459-475.

Lungu V., Covacef Z., Chera K., 2012. Bijuterii antice din aur din olecțiile Muzeului de Istorie Națională şi. Arheologie Constanța. Biblotheca Tomitana Vol. VI. Constanța, Ex Ponto. 147 p.

Marčenko I.I., Limberis N.J., 2008. Römische Importe in sarmatischen und maiotischen Denkmälern des Kubangebietes. Simonenko A., Marčenko I.I., Limberis N.J. Römische Importe in sarmatischen und maiotischen Gräbern. Archäologie in Eurasien. Bd. 25. Mainz, von Zabern, S. 267-400.

Margulies E., 1967. Cloisonné enamel. Survey of Persian Art, vol. II. Tehran, Persian Art; London, Oxford University Press; Tokyo, Teiji Shobo, pp. 779-783.

Mitchell S., 1982. Regional Epigraphic Catalogues of Asia Minor. Vol. 2: The Ankara District: The Inscriptions of North Galatia. Oxford, British Archaeological Reports. 461 p.

Mordvintseva V.I., Zaitsev Y.P., 2003. The Nogaichik Burial-Mound in the Steppes of the Crimea. Ancient Civilizations from Scythia to Siberia, vol. 9, pp. 193-257.

Müller-Karpe A., 2018. Die Juwelen der Königin Berenike. Antiker Schmuck zwischen Raubgrabungen und Wissenschaft. Festschrift für Heide Froning. Studies in Honour of Heide Froning. Istanbul, E Yayinlari, S. 313-334.

Nenna M.-D., 1999. Les Verres. Exploration archéologique de Délos, 37. Paris, Athènes, École Française d'Athènes. 216 p.

Parachaud K., 2015. Présences “celtiques” en Méditerranée orientale au regard des cultures matérielles de La Tène (Ve-Ier siècle av. n. è.). Vol. 1-2. Université Toulouse-Jean Jaurès. 174 p. 
Parker V., 2018. Deiotarus: zur Karriere eines römischen Klientelkönigs. Electrum, vol. 25, S. 187-208. DOI : http:// doi.org/10.4467/20800909EL.18.009.8929.

Pfeiler B., 1970. Römischer Goldschmuck des ersten und zweiten Jahrhunderts n. Chr. nach datierten Funden. Mainz, von Zabern. $136 \mathrm{~S}$.

Pfeiler-Lippitz B., 1972. Späthellenistische Goldschmiedearbeiten. Antike Kunst, Jg. 15, Heft 2, S. 107-119.

Pfrommer M., 1990. Untersuchungen zur Chronologie früh-und hochhellenistischen Goldschmucks (Istanbuler Forschungen 37). Tübingen: E. Wasmuth. $470 \mathrm{~S}$.

Plantzos D., 1999. Hellenistic Engraved Gems. Oxford, Clarendon Press. 148 p.

Platz-Horster G., 2010. Kleine Praser and Chromium-bearing Chalcedonies. About a Small Group of Engraved Gems. Pallas, vol. 83, pp. 179-202.

Pougatchenkova G., 1978. Les trésors de Dalverzine-Tépé. Leningrad, Eìd. d'art Aurore. 102 p.

Regional epigraphic catalogues of Asia Minor II: the Ankara district, the inscriptions of North Galatia. URL: https://epigraphy.packhum.org/text/267821 (accessed 30.11.2020).

Rice K.E., 2016. A Tomb with a View: Constructing Place and Identity in the Funerary Monuments of Hellenistic Anatolia. Dissertation. University of North Carolina at Chapel Hill. Chapel Hill. 578 p.

Rolley C., 2003. Le cratère. La tombe princière de Vix. Paris, Picard et Société des amis du musée du Châtillonais, pp. $76-143$.

Rosenberg M., 1921. Geschichte der Goldschmiedekunst auf technischer Grundlage. Zellenschmelz. Bd. 1-2. Frankfurt, Joseph Baer \& Co. $80 \mathrm{~S}$.

Rudenko S.I., 1962. Die Sibirische Sammlung Peters I. Sammlung archäologischen Quellen D3-9. Moskau, Leningrad, Verlag der Akademie der Wissenschaften der UdSSR. 67 S.

Ruxer M.S., Kubczak J., 1972. Naszyjnik grecki w okresie hellenistycznym i rzymskim. Warsaw, Poznań, Państwowe Wydawn. Naukowe, Oddział w Poznaniu. 272 p.

Sarianidi V.I., 1985. Baktrisches Gold. Leningrad, Aurova-Kunstverlag. 264 S.

Ščepinskij A.A., 1994. Über die Aristokratie der Sarmaten im nördlichen Schwarzmeergebiet. Zeitschrift für Archäologie, Bd. 28, S. 87-106.

Segall B., 1938. Katalog der Goldschmiede-Arbeiten. Museum Benaki. Athen, Museum Benaki. 220 S.

Shaw I., Bunbury J., Jameson R., 1999. Emerald mining in Roman and Byzantine Egypt. Journal of Roman Archaeology, vol. 12, p. 203-215.

Spickermann W., 2006. "Deiotaros", Der Neue Pauly, Herausgegeben von: Hubert Cancik, Helmuth Schneider (Antike), Manfred Landfester (Rezeptions- und Wissenschaftsgeschichte). URL: http://dx.doi.org/10.1163/ 1574-9347_dnp_e313010 (accessed 22.09.2020).

Stassinopoulou E., 2012. The Golden Jewels and the Silver Vases. The Antikythera Shipwreck, the Ship, the Treasures, the Mechanism. Exhibition catalogue. Athens, Hellenic Ministry of Culture and Tourism - National Archaeological Museum, pp. 146-151.

Strobel K., 2002. Die Staatenbildung bei den kleinasiatischen Galatern. Politisch-historische und kulturelle Prozesse im hellenistischen Zentralanatolien. Brückenland Anatolien? Ursachen, Extensität und Modi des Kulturaustausches zwischen Anatolien und seinen Nachbarn. Tübingen, Attempto, S. 231-293.

Syme R. 1995. Deiotarus. Syme R. Anatolica. Studies in Strabo. Oxford, Clarendon Press, pp. 127-136.

Tarditi C., 2016. Bronze Vessels from the Acropolis. Style and Decoration in Athenian Production Between the Sixth and the Fifth Centuries BC. Thiasos Monografie. Vol. 7. Roma, Edizioni Quasar. 410 p.

Treister M.Y., 1997. New Discoveries of Sarmatian Complexes of the $1^{\text {st }}$ Century AD. A Survey of Publications in VDI. Ancient Civilizations from Scythia to Siberia, vol. 4, pp. 35-100.

Treister M., 2002. Two Golden Bracelets from Olbia in the Walters Art Gallery. Ancient Civilizations from Scythia to Siberia, vol. 8, pp. 17-68.

Treister M.Y., 2004a. Cloisonné-and Champlevé-decoration in the Gold Work of the Late Hellenistic - Early Imperial Periods. Acta Archaeologica, vol. 75, no. 2, pp. 189-219.

Treister M.Y., 2004b. Polychrome Necklaces from the Late Hellenistic Period (On the Question of the Origin of Necklaces with Butterfly-shaped Pendants). Ancient Civilizations from Scythia to Siberia, vol. 10, pp. 199-257. 
Treister M., 2005. On a Vessel with Figured Friezes from a Private Collection, on Burials in Kosika and Once More on the "Ampsalakos School”. Ancient Civilizations from Scythia to Siberia, vol. 11, nos. 3-4, pp. 199-255.

Treister M., 2006. Late Hellenistic Polychrome Necklaces. Common Ground: Archaeology, Art, Science, and Humanities, Proceedings of the XVI International Congress of Classical Archaeology. Oxbow Monograph XX. Oxford, Oxbow Books, pp. 518-522.

Tselekas P., 2012. The Coins. The Antikythera Shipwreck, the Ship, the Treasures, the Mechanism. Exhibition catalogue. Athens : Hellenic Ministry of Culture and Tourism - National Archaeological Museum, pp. 216-226.

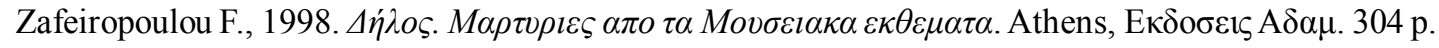

Zinc S., 2019. Polychromy, architectural, Greek and Roman. Oxford Classical Dictionary. DOI: https://doi.org/ 10.1093/acrefore/9780199381135.013.8184.

Zwierlein-Diehl E., 2007. Antike Gemmen und Ihr Nachleben. Berlin, Walter de Gruyter. 567 S.

\section{Information About the Author}

Mikhail Yu. Treister, Doctor of Sciences (History), Researcher, German Archaeological Institute, Podbielskiallee,69-71, 14195 Berlin, Germany, mikhail.treister@dainst.de, mikhailtreister@yahoo.de, https://orcid.org/0000-0001-7451-3325

\section{Информация об авторе}

Михаил Юрьевич Трейстер, доктор исторических наук, научный сотрудник, Германский археологический институт, Подбельскиаллее, 69-71, 14195 г. Берлин, Германия, mikhail.treister@dainst.de, mikhailtreister@yahoo.de, https://orcid.org/0000-0001-7451-3325 